\author{
MANUEL LlORCA-JaÑA* \\ Claudio Robles Ortiz ${ }^{* *}$ \\ JuAn NaVARrete-Montalvo*** \\ Roberto Araya ValenZuela****
}

\title{
LA AGRICULTURA Y LA ÉLITE AGRARIA CHILENA \\ A TRAVÉS DE LOS CATASTROS AGRÍCOLAS, C. $1830-1855^{1}$
}

\begin{abstract}
RESUMEN
Este artículo analiza la situación del sector agropecuario y la composición de la élite agraria en Chile en la primera mitad del siglo XIX, un periodo insuficientemente tratado en la literatura especializada. Para ello hemos empleado información procedente de fuentes escasamente utilizadas en la historiografía agraria, como son El Agricultor y, especialmente, el Catastro Agrícola. A partir de este último, hemos construido y procesado una base de datos de medio millón de registros provenientes de los tres primeros catastros agrícolas, realizados en 1832, 1838 y 1852. Junto con establecer las razones del atraso del sector agrario, y una muy desigual distribución tanto de la propiedad de la tierra como del ingreso agrícola, nuestros resultados indican una notable persistencia de las élites agrarias entre fines de la Colonia y las primeras décadas de Chile independiente, así como una significativa correlación entre la clase de grandes agricultores de mayores ingresos y la élite política.
\end{abstract}

Palabras claves: Chile, siglo XIX, agricultura, catastro, élites, hacendados, desigualdad.

\section{Abstract}

This article assesses the state of the agrarian sector and the composition of the Chilean agrarian elite during the first half of the nineteenth century, a rather unexplored period

* Ph.D. Leicester University. Profesor titular, Departamento de Economía, Universidad de Santiago de Chile. Correo electrónico: manuel.1lorca@usach.cl

${ }^{* *}$ Ph.D. University of California-Davis. Profesor asociado, Departamento de Economía, Universidad de Santiago de Chile. Correo electrónico: claudio.robles@usach.cl

${ }_{* * *}$ Magíster (c) en Historia, Universidad de Chile. Investigador asociado, CIHEAP-FAE, Universidad de Santiago de Chile. Correo electrónico: juandonm@gmail.com

${ }^{* * * *}$ Magíster en Historia, Universidad de Santiago de Chile. Investigador asociado, CIHEAP-FAE, Universidad de Santiago de Chile. Correo electrónico: robertoarayav@yahoo.es

${ }^{1}$ Este artículo fue financiado por el proyecto FONDECYT Regular No 1150161 y Proyectos Basales USA1498 USACH-MECESUP. Los autores están muy agradecidos de Ricardo Couyoumdjian, Jaime Rosenblitt, Jean Pierre Flores, Enzo Videla, Jorge Gelman y Francisco Betancourt por su ayuda para identificar y conseguir fuentes de gran utilidad para la elaboración de este estudio. 
in Chile's agrarian historiography. We have used several untapped sources such as the Catastro Agrícola and El Agricultor. From the former we have built and processed a half a million records database. From the former we have built and processed a database consisting of half a million records from the first three agricultural censuses of 1832, 1838 and 1852. We have explained why the agricultural sector was so backwards in Chile, while also established a very unequal distribution of both land tenure and agricultural income. Finally, our results show a great persistence within the composition of the agrarian elites between late colonial times and the first decades of republican Chile, as well as a significant correlation between the large landowners with highest agricultural income and the political elite.

Keywords: Chile, nineteenth century, agriculture, cadastre, elites, landowners, inequality.

Recibido: Octubre 2016.

Aceptado: Marzo 2017.

\section{INTRODUCCIÓN}

A pesar de su creciente inserción en la economía mundial luego de la Independencia, Chile siguió siendo, fundamentalmente, una sociedad rural y una economía agraria hasta al menos la década de 1850. Al respecto, un visitante británico en Chile a mediados de la década de 1820 fue bastante concluyente: "the inhabitants of Chile are chiefly taken up with agricultural and mining. The manufactures are of trifling importance" ${ }^{2}$. Si bien la información cuantitativa para ese periodo es precaria, la preeminencia del sector agropecuario es evidente. En 1865, primer año para el que existe información en la recién publicada compilación de estadísticas históricas de Chile, la población rural representaba un $71 \%$ del total, una tasa significativamente alta y que, en términos de desarrollo económico, se asocia a una estructura económica basada en actividades primarias, como la agricultura y la ganadería. Según el censo de población de 1854, solo había seis ciudades con más de diez mil habitantes ${ }^{3}$.

En cuanto a la distribución de la fuerza laboral, para 1854-1859 la agrícola era un $42 \%$ del total, muy por sobre la de cualquier otro sector económico. Por su parte, las estimaciones de PIB sectorial más tempranas para el sector agrario corresponden a 1860 $\mathrm{y}$, por tanto, son posteriores al periodo cubierto por este artículo (c.1830-1855) ${ }^{4}$. No obstante, cabe destacar que ese año, y de hecho hasta 1869 , de todos los sectores para

\footnotetext{
${ }^{2}$ Alexander Caldcleugh, Travels in South America, during the years, 1819-20-21, London, John Murray, 1825 , vol. I, p. 347.

${ }^{3}$ José Díaz, Rolf Lüders y Gert Wagner, Chile 1810-2010. La república en cifras, Santiago, Ediciones UC, 2016, pp. 698-700, 702.

${ }^{4}$ Lamentablemente las cifras de fuerza de trabajo de la agricultura están agregadas con las de pesca, pero podemos suponer de forma razonable que la mayoría de estos trabajadores se dedicaban a la agricultura durante este periodo. Díaz, Lüders y Wagner, op. cit., p. 660. No obstante, en buena medida las estimaciones para los primeros años de la década de 1860 están basadas en cifras de 1870 en adelante, por lo que estas estimaciones deben ser tomadas con precaución.
} 
los que se dispone de cifras de PIB sectorial, el sector agrícola es el más importante ${ }^{5}$. Además, se puede considerar la participación de las exportaciones agrícolas, pero dada la precariedad de los transportes internos en Chile, la mayor parte de la producción agrícola chilena se consumía internamente, por lo que este indicador subestima la importancia del sector. Aun así, las cifras oficiales, disponibles desde 1844, indican que para 1844-1859 la participación del sector agrícola en el total exportado fue $24 \%$, por debajo del cobre, que registró un 39\%, y de la plata y oro combinados, de un $30 \%{ }^{6}$. Es importante señalar que en la práctica todo el cobre que se producía en Chile y buena parte del oro y la plata se exportaban, lo que no ocurría con los productos agropecuarios. Si tratamos de corregir esta distorsión, según estimaciones de Benjamín Vicuña Mackenna, hacia 1855 el valor de la producción anual agrícola de Chile era de unos $\$ 25.000 .000^{7}$, mientras que el valor total de las exportaciones chilenas, excluido el sector agrícola fue de $\$ 12.000 .000^{8}$. Incluso, si comparamos el valor de la producción agrícola de los fundos que pagaban el catastro en 1852 (\$7.400.000) con las exportaciones no agrícolas de Chile de ese año (\$8.300.000), la preeminencia del sector agrícola queda demostrada9 .

No obstante su importancia, la agricultura de la primera mitad del siglo XIX ha sido insuficientemente estudiada porque, en primer lugar, la producción historiográfica se ha concentrado en debates referidos a periodos posteriores. Los principales trabajos se enfocaron en analizar si la sociedad rural de Chile Central mantuvo su carácter "tradicional" y la agricultura permaneció como un sector "atrasado" o si, por el contrario, se modernizó en algún grado, al participar de la transición al capitalismo que experimentó la economía chilena desde mediados del siglo $\mathrm{XIX}^{10}$. En directa relación con ese debate, la historiografía agraria ha discutido también el impacto de la expansión agraria que tuvo lugar entre 1850 y 1930 sobre los sistemas de trabajo rural. Mientras que los trabajos de la década de 1970 afirmaron la persistencia del inquilinaje, aunque en una modalidad más precaria, la historiografía revisionista ha destacado la verificación de un gradual proceso de proletarización de la fuerza de trabajo hacenda ${ }^{11}$. Desde la perspectiva de la

\footnotetext{
${ }^{5}$ Díaz, Lüders y Wagner, op. cit.

${ }^{6}$ Estimaciones propias sobre la base de cifras disponibles en Chile, Estadistica Comercial de la República de Chile, Santiago, Imprenta de los Tribunales, 1844-1859.

${ }^{7}$ Benjamín Vicuña Mackenna, La agricultura de Chile, memoria presentada a la Sociedad de Agricultura, Santiago, Imprenta Chilena, 1856.

${ }^{8}$ Chile, Estadistica Comercial de la República de Chile, Santiago, Imprenta de los Tribunales, 1855.

${ }^{9}$ Chile, Estadistica Comercial de la República de Chile, Santiago, Imprenta de los Tribunales, 1852.

${ }^{10}$ Arnold J. Bauer, Chilean Rural Society from the Spanish Conquest to 1930, Cambridge, Cambridge University Press, 1975; Cristóbal Kay, Comparative Development of the European Manorial System and the Latin American Hacienda System: An Approach to a Theory of Agrarian Change for Chile, PhD. diss., Brighton, University of Sussex, 1971; Claudio Robles Ortiz, Agrarian Capitalism in an Export Economy. Chilean Agriculture in the Nitrate Era, 1880-1930, Ph.D. diss., Davis, University of California, 2002.

${ }^{11}$ Arnold J. Bauer, "Chilean Rural Labor in the Nineteenth Century", in American Historical Review, $\mathrm{N}^{\circ}$ 4, vol. 76, Bloomington, 1971, pp. 1076-1082; Cristóbal Kay, "The development of the hacienda system, 1850-1973", in Kenneth Duncan and Ian Rutledge (eds.), Land and Labour in Latin America. Essays on the Development of Agrarian Capitalism in the Nineteenth and Twentieth Centuries, Cambridge, Cambridge University Press, 1977, pp. 103-139; Roberto Santana, "Un cas de proletarianisation rurale: l'inquilino", in Cahiers du Monde Hispanique et Luso-Bresilien, No 28, Toulouse, 1977, pp. 73-90; Arnold J. Bauer, "Landlord and Campesino in the Chilean Road to Democracy", in Evelyn Huber \& Frank Safford (eds.), Agrarian Structure \& Political Power. Landlord and Peasant in the Making of Latin America, Pittsburgh, University of Pittsburgh
} 
historia económica, en tanto, la noción convencional respecto del pobre desempeño del sector agropecuario en la economía exportadora (c.1850-1930) ha sido cuestionada en trabajos posteriores que muestran su crecimiento y diversificación en función del mercado interno ${ }^{12}$. Asimismo, la interpretación convencional sobre el desempeño empresarial de los grandes terratenientes, como una clase rentista de agricultores ineficientes y ausentistas, ha sido revisada por trabajos sobre sectores de agricultores emprendedores y "modernizadores" y las instituciones creadas por ellos para el fomento agrícola, como la Sociedad Nacional de Agricultura (1869) ${ }^{13}$. Además, debe notarse que esta interpretación propuesta por la historiografía agraria de la década de 1970 informó el trabajo de autores chilenos a fines de los 1980 y comienzos de $1990^{14}$.

Al mismo tiempo, el estudio de la agricultura del periodo que se extiende entre la Independencia y la década de 1850 enfrenta el importante obstáculo representado por la menor disponibilidad o, en algunos aspectos, ausencia de fuentes de información, especialmente estadísticas. Con la importante excepción de iniciativas en materia tributaria, como veremos, la era de las modernas estadísticas oficiales producidas por instituciones estatales para los distintos sectores de la economía comenzó en Chile a mediados de la década de 1840 y su extensión al sector agropecuario fue más bien tardía, lo que dificulta el establecimiento de tendencias sobre la base de series de información cuantitativa. De manera similar, y en contraste con la historiografía agraria de otros países latinoamericanos, una de las grandes limitaciones para el estudio de la temprana historia agraria chilena es la escasez de fuentes documentales producidas por la operación de las propiedades agrícolas, como libros de cuentas, correspondencia comercial y documentación de administración. De hecho, uno de los principales factores que explica esa falta de documentación es la tardía incorporación de la contabilidad moderna por parte de los grandes propietarios. Así, tan tarde como 1841, un redactor de El Agricultor observaba: “ ¡Cuan pocos son, en efecto, los agricultores que llevan cuenta en forma de los trabajos que emprenden en sus fundos!"; por ello, además, exhortaba a su adopción, señalando: "la contabilidad es la sonda que debe tener en mano el comerciante, el fabricante, el agricultor", porque "no hay censor mas severo e imparcial de nuestros procedimientos que un libro de cuentas. Rómpase este libro y quedaremos a oscuras"15.

A pesar de que los principales debates historiográficos sobre el sector agrícola se han enfocado en periodos posteriores y que la menor disponibilidad de fuentes dificulta exa-

Press, 1995, pp. 21-38 y Claudio Robles Ortiz, “Agrarian Capitalism and Rural Labour: The Hacienda System in Central Chile, 1870-1920”, in Journal of Latin American Studies, N 41, vol. 3, London, 2009, pp. 493-526.

${ }^{12}$ Carmen Cariola y Osvaldo Sunkel, Un siglo de historia económica de Chile, 1880-1930. Dos ensayos y una bibliografia, Santiago, Editorial Universitaria, 1991; Claudio Robles Ortiz, "La producción agropecuaria chilena en la 'Era del Salitre' (1880-1930)”, en América Latina en la Historia Económica, N ${ }^{\circ} 32$, México D.F., julio-diciembre 2009, pp. 113-136.

${ }^{13}$ Claudio Robles Ortiz, Hacendados progresistas y modernización agraria en Chile Central, 1850-1880, Editorial Universidad de Los Lagos, 2007 y "Controlando la mano invisible: la Sociedad Nacional de Agricultura y el mercado de maquinaria agrícola (1889-1922)", en Historia, № 42, vol. I, Santiago, 2009, pp. 203-233.

${ }^{14}$ José Bengoa, El poder y la subordinación. Historia social de la agricultura chilena, Santiago, Ediciones SUR, 1988, tomo I; Haciendas y campesinos. Historia social de la agricultura chilena, Santiago, Ediciones SUR, 1990, tomo II e Historia rural de Chile Central, Santiago, LOM Ediciones, 2015, tomos I y II.

${ }^{15}$ El Agricultor, N 19, Santiago, octubre 1841. 
minar la primera mitad del siglo XIX, profundizar en el estudio de la agricultura en ese periodo es importante per se para estudiosos de la historia social y económica. Es relevante para examinar no solo el grado de atraso en que se encontraba el agro a fines de la Colonia e inicios de la era republicana sino, también, asuntos relevantes de la economía chilena, como la distribución interna de mercaderías, patrones de consumo y, desde luego, la concentración de la riqueza. Estudiando el sector agrícola temprano podemos interiorizarnos más sobre la desigualdad en la distribución del ingreso y la riqueza en las primeras décadas de Chile independiente, un periodo de transición entre la Colonia y la "Primera Globalización" (c.1870-1913). Asimismo, es posible analizar el grado de persistencia de la institucionalidad colonial en la economía chilena de este periodo de transición, por ejemplo, en términos de la (re)configuración de las élites agrarias.

Para abordar esas problemáticas, en este artículo empleamos la información derivada del denominado Catastro Agrícola, el nuevo impuesto sobre el sector agropecuario que se introdujo en 1831. Para su recaudación se implementaron sendos censos agrícolas (o “catastros", de donde viene el nombre del impuesto). Así, el primer catastro, ejecutado entre 1832 y 1834, fue el primer censo agrícola que involucró la totalidad de la Repúbli$\mathrm{ca}^{16}$. Los sucesivos catastros dieron lugar a una masa de información que no tiene equivalente en América Latina y que convirtió a Chile en un pionero en las estadísticas agrarias en la región, al menos en cuanto a censar la totalidad del territorio rural nacional se refiere, identificando la totalidad de los predios agrícolas, así como parte de la inversión contenida en los mismos (e.g. ganado y plantas de viña ${ }^{17}$. La revisión de la literatura especializada reciente (en historia económica) demuestra que semejante información no existe para ningún país latinoamericano antes de fines de la década de $1850^{18}$. Aún más, a pesar de su riqueza, esta fuente no fue utilizada en estudios de la historia económica chilena, salvo para tratar tópicos muy específicos ${ }^{19}$. En buena medida ello se explica -al

\footnotetext{
${ }^{16}$ La intención original de los gobiernos de José Joaquín Prieto era que los catastros debían realizarse cada cuatro años. El primero se terminó en 1834, el segundo en 1838 (cumpliendo así dicho plazo), pero entre el término del segundo y el del tercero, pasaron catorce años. Los gobiernos de turno decidieron no realizar catastros intermedios producto del alto costo de realizar los mismos y también porque existía consenso político que el de 1837-1838 fue un muy buen censo agrícola. Véase, por ejemplo, Sesión de la Cámara de Diputados, 20 de octubre de 1843, en Chile, Sesiones de los Cuerpos Legislativos de la República de Chile, Santiago, Imprenta Cervantes, 1843.

${ }^{17}$ Incluso en España, el primer catastro nacional para el sector rural parte en 1840, casi diez años después que el primer catastro en Chile. Lily Álvarez Correa, Catastro de propiedad en Chile: orígenes y evolución, tesis doctoral, Barcelona, Universitat de Barcelona, 2014, p. 65.

${ }^{18}$ Solo para algunas provincias del Río de la Plata existe información comparable, extensamente trabajada por Jorge Gelman y Daniel Santilli, pero la cobertura geográfica de los mismos es bastante limitada, muy inferior a la de los catastros chilenos. Jorge Gelman y Daniel Santilli, De Rivadavia a Rosas: Desigualdad y crecimiento económico, Buenos Aires, Siglo Veintiuno Editores, 2006; Jorge Gelman y Daniel Santilli, "Una creciente desigualdad. La propiedad de la tierra en Buenos Aires entre 1839 y 1855", en Investigaciones de Historia Económica, vol 18, № 1, Madrid, 2010, pp. 11-33 y “¿Cómo explicar la creciente desigualdad? La propiedad de la tierra en Buenos Aires entre 1839 y 1867”, en Jorge Gelman (comp.), El mapa de la desigualdad en la Argentina del siglo XIX, Rosario, Prohistoria, 2011, pp. 171-217.

${ }^{19}$ Por ejemplo, trabajos conocidos que emplearon información fragmentaria proveniente de los catastros son los de Arnold Bauer, Expansión económica en una sociedad tradicional: Chile central en el siglo XIX, Santiago, Universidad Católica de Chile, Instituto de Historia, 1970; Jaime Eyzaguirre, "El primer censo agrícola chileno", en Boletín de la Academia Chilena de la Historia, vol. 90, º 1, Santiago, 1978-1979, pp.
} 
menos en los trabajos más pretéritos- por la inexistencia de medios informáticos que, como es el caso de los empleados en este trabajo, permiten procesar grandes cantidades de datos cuantitativos y establecer fundadamente patrones y tendencias respecto de los procesos estudiados.

De este modo, usando diversas bases de datos que hemos construido con la información de una fuente primaria extraordinariamente rica como el Catastro Agrícola, en este artículo buscamos contribuir al estudio del sector agropecuario entre la Independencia y mediados del siglo XIX, enfocándonos en el análisis de la distribución del ingreso y la riqueza agrícola, a través de la determinación de la composición de las "grandes fortunas" de dicho sector. Nuestra principal fuente de información se encuentra en el Archivo Nacional de Chile. Para los dos primeros catastros hemos consultado el Fondo Dirección General de Estadísticas, tomos I-VII, Registro de Predios Rústicos (ANCH-FDGE de aquí en adelante), mientras que para el tercer catastro hemos consultado una versión impresa en la Biblioteca Nacional ${ }^{20}$. Complementariamente, hemos utilizado otras fuentes relativamente poco utilizadas con anterioridad para caracterizar el sector agrícola durante nuestro periodo de análisis, como El Agricultor (1838-1848), El Mensajero de la Agricultura (1856-1857), las sesiones de los Cuerpos Legislativos y los reportes consulares británicos.

En términos específicos, el primer objetivo de este artículo es identificar y caracterizar a la élite de grandes propietarios agrícolas de Chile c.1830-1855, analizando, también, en qué medida esta se modificó - o no- entre la Colonia tardía y la República temprana. A continuación, buscamos establecer el grado de concentración de la riqueza en el sector agropecuario, la cual puede considerarse como una aproximación válida a la concentración de la riqueza en el país (dado el peso del sector agrícola en el conjunto de la economía, como se ha señalado). Asimismo, nos interesa caracterizar la gran propiedad agrícola en función de la información cuantitativa disponible en los censos agrícolas derivados del Catastro, considerando variables tales como extensión de los predios, stock de ganado y plantas de viña. En conjunto, las respuestas a estas preguntas son relevantes para establecer la composición de la élite agraria y explicar la situación del sector agropecuario entre la Independencia y mediados del siglo XIX. En concreto, dispondremos de nuevos elementos de juicio para determinar si existió una correlación entre, por una parte, la continuidad o los cambios en la composición, el número y la magnitud de las fortunas y, por otra, el desempeño del sector. Así, la relevancia del trabajo puede explicarse en términos de su contribución para abordar el siguiente problema: si el sector no se transformó, fue por la persistencia del mismo núcleo de grandes terratenientes de origen "colonial" o, por el contrario, en qué medida su eventual transformación puede asociarse al ingreso de nuevas fortunas y, si ese fuera el caso, cuál fue su naturaleza y desde cuándo ingresaron a la élite agraria.

79-126; Rolando Mellafe, Sociedad y población rural en la formación de Chile actual: La Ligua 1700-1850, Santiago, Universidad de Chile, 1988 y más recientemente los de Álvarez Correa, op. cit., y Pablo Lacoste, El Pisco nació en Chile, Santiago, RIL Editores, 2016.

${ }^{20}$ Chile, Estado que manifiesta la renta agrícola de los fundos rústicos para deducir el impuesto anual establecido, 1852, Valparaiso, Imprenta del Diario, 1855. 
El artículo se estructura en otras cuatro partes. En la segunda parte tratamos los orígenes del catastro y realizamos una breve descripción del mismo. A continuación, caracterizamos el sector agrícola en su conjunto, principalmente con los registros cuantitativos de las bases de datos agregadas procedentes de los tres censos analizados, pero también usando información de otras fuentes, como El Agricultor, órgano oficial de la primera Sociedad de Agricultura. Esta sección documenta el atraso del sector y establece sus causas, pero también aporta evidencia sobre el número e ingreso anual de los fundos, el stock de ganado y los viñedos (desagregados por provincias). La siguiente sección analiza las principales fortunas del sector agrícola (identificando las cuarenta y ocho mayores en cada censo), e indagamos sobre el perfil de los líderes familiares de las mismas, incluyendo sus nexos con la élite política republicana y la vieja élite colonial. Finalmente, realizamos un análisis comparativo entre las grandes fortunas agrícolas y las grandes fortunas de otros sectores de la economía, para determinar en qué medida los grandes terratenientes chilenos diversificaron su cartera de inversión.

\section{ORÍGENES DEL CATASTRO Y DESCRIPCIÓN DEL MISMO}

En 1831, bajo la primera presidencia (1831-1836) ${ }^{21}$ de José Joaquín Prieto, y siendo Manuel Rengifo (1793-1845) ministro de Hacienda, se introdujo en Chile un nuevo impuesto agrícola, denominado contribución catastral, el que reemplazó a las alcabalas subastadas, impuestos de licores y el cabezón ${ }^{22}$. Este importante cambio impositivo fue parte de una reforma fiscal mayor que tenía como propósito introducir contribuciones directas en Chile y reemplazar al diezmo en un futuro cercano ${ }^{23}$. Una parte menos conocida del origen del catastro, nunca antes mencionada por otros autores, y resaltada por fuentes británicas contemporáneas (reportes consulares), es que el catastro también fue introducido exclusivamente ${ }^{24}$ para pagar parte de los intereses y el capital del primer

\footnotetext{
${ }^{21}$ Cabe destacar que José J. Prieto fue reelecto por un segundo periodo, de 1836 a 1841. Esto es, los dos primeros censos agrícolas de Chile (1832-1834 y 1837-1838) fueron implementados durante sus dos mandatos.

${ }^{22}$ Sesión de la Cámara de Senadores, 15 de octubre de 1831, en Chile, Sesiones de los Cuerpos Legislativos de la República de Chile, Santiago, Imprenta Cervantes, 1832. Cabe destacar que el catastro convivió en paralelo por casi dos décadas con el diezmo (herencia colonial), otro impuesto agrícola pagado al Estado por los dueños de algún predio. Álvarez Correa, op. cit., p. 8. En teoría, los dueños de predios agrícolas debían pagar un 10\% de impuesto sobre el valor de sus cosechas, recolección y cría de sus ganados. Por su parte, el catastro también convivió con una alcabala que gravaba los contratos de compra venta de propiedades rurales (y urbanas), así como el arriendo de las mismas. Alcabala, Disposiciones relativas a esta contribución o derecho, 17 de marzo de 1835.

${ }^{23}$ En 1835, el ministro de Hacienda de turno declaraba, en la memoria anual al Congreso, que el catastro: “[está] destinado a subrogar la alcabala y demás gabelas que se suprimieron cuando se creó, servirá de ensayo a la contribución directa, y denotará si es oportuno refundir en un impuesto territorial el tributo del diezmo que ofrece tantas dificultades para recaudarlo". Al respecto, cabe destacar que no fue sino hasta 1848 que se comenzó a legislar para suprimir el diezmo y finalmente, fue en 1853 cuando se creó un nuevo impuesto agrícola, llamado contribución territorial, que reemplazó de forma definitiva al diezmo. El nuevo impuesto fue fundido en 1861 con el catastro, para crear un impuesto agrícola único. Vicuña Mackenna, op. cit., p. 57; Eyzaguirre, op. cit., p. 95; Álvarez Correa, op. cit., pp. 3, 126-128.

${ }^{24}$ El artículo 13 de la ley promulgada el 23 de octubre de 1834 indica explícitamente que lo recaudado por el catastro se destinará de modo exclusivo al pago de parte de la deuda externa con el Reino Unido (no siendo suficiente para pagar tanto intereses como el principal).
} 
préstamo tomado por Chile en Londres, impago desde mediados de los años $1820^{25}$. Los tenedores de bonos del primer empréstito de Chile en Londres presionaron para que el Estado chileno generase una nueva fuente de ingreso fiscal para cumplir con los pagos y dieron especial atención a su posterior ejecución. De hecho, después del terremoto que azotó al sur de Chile en 1835, el gobierno decidió eximir de manera parcial del pago del catastro a las provincias más afectadas del país (algunas pagarían solo el 50\% y otras solo el $25 \%$ del impuesto catastral asignado $)^{26}$, pero tal medida fue contestada con dureza por el consulado británico en Chile. El Cónsul General percibió tal medida como "an infraction of that Bond entered into voluntarily by the government, ratified by the Congress", agregando que los ingresos del catastro debían ser considerados como una "property over which (the Chilean government) no longer possessed any control"27.

A su vez, en lugar de ser encargada a agentes privados (como era el caso de otros impuestos), su recaudación fue confiada a funcionarios de gobierno, en concreto de la Factoría General del Estanco ${ }^{28}$. Con este propósito se estableció un importante nuevo aparato burocrático, también parte de reformas que pretendían mejorar la recolección de gravámenes. La nueva entidad era encabezada por la Junta Central del Catastro, integrada por cinco miembros (designados por el Intendente), a la que le correspondía nombrar una junta departamental, compuesta también de cinco miembros (el Gobernador, el administrador del estanco y tres vecinos pudientes). A su vez, la Junta Departamental nombraba a una junta parroquial, integrada por el párroco local, un delegado del Gobernador y tres vecinos adinerados, quienes finalmente eran responsables de recolectar la información primaria, la que luego debía ser validada por las dos juntas superiores y luego enviada al Ministerio de Hacienda.

Dada la magnitud de la tarea encomendada a la Junta Central del Catastro, los gobiernos de turno dieron gran importancia a la demarcación de terrenos, con el fin de subsanar potenciales litigios entre vecinos. Una figura clave en este proceso fueron los agrimensores. Incluso, antes de implementado el catastro, cabe mencionar que ya desde 1823 el gobierno chileno había contratado un científico francés (Carlos Ambrosio Lozier, ingeniero geógrafo), y luego a Claudio Gay en 1830 y a Amado Pissis en 1848, para realizar labores de reconocimiento del territorio chileno, ejecutando cartas y planos topográficos. Sus trabajos fueron fundamentales para ejecutar los catastros de los años 1830 y $1850^{29}$, toda vez que no se contaba con registros previos de propiedades rurales. A principios de la década de 1820 el gobierno ya constataba que un $75 \%$ de los pleitos judiciales en Chile se debían a los datos inexactos sobre demarcaciones de terrenos y deslindes de propiedades, por lo que se hacía imperioso el empleo de agrimensores alta-

25 "British Consular Reports from Chile", in National Archives, Reino Unido (en adelante FO); John Walpole a Viscount Palmerston (London), Santiago, 14 diciembre 1835, en FO 132/4.

${ }^{26}$ Sesiones de los Cuerpos Legislativos. Cámara de Diputados. Acta, sesión 5 octubre 1835.

${ }^{27}$ John Walpole a Viscount Palmerston, op. cit.

${ }^{28}$ Chile, Principios elementales de derecho administrativo chileno, Santiago, Imprenta Nacional, 1859, p. 307; Sergio Villalobos, Estudios y ensayos en torno a la historia de Chile, Santiago, Editorial Universitaria, 2010, p. 237.

${ }^{29}$ El trabajo de Amado Pissis en particular, y que duró varios lustros, se considera de gran importancia para la cartografía nacional chilena. Véase Álvarez Correa, op. cit., pp. 116-120. 
mente calificados. Para ello, ese mismo año, se recomendó, incluso, la creación de una escuela de topografía en el Instituto Nacional, así como una oficina que debía desempeñar las funciones que después desempeñó el Conservador de Bienes Raíces ${ }^{30}$. Posteriormente, en 1831, año de promulgación de la ley del catastro, el gobierno sacó en paralelo otro cuerpo legal, que especificaba de forma clara el tipo de formación que debían recibir los agrimensores en Chile ${ }^{31}$.

En términos operativos, originalmente, el catastro equivalía a un 4\% del valor del ingreso anual estimado de todos los fundos rústicos cuya producción estuviese avaluada en $\$ 25$, o más, por año ${ }^{32}$. Cabe destacar que se gravaba solo la producción que se destinaba al mercado, no aquella producida para autoconsumo. Sin embargo, debido a dificultades iniciales en su cobro, así como a reclamos de algunos propietarios por el alto porcentaje del nuevo impuesto, prontamente se optó por reducir dicha tasa a $3 \%{ }^{33}$. La meta de los gobiernos de turno era recaudar alrededor de $\$ 100.000$ anuales a través de este gravamen, la que se alcanzó recién a principios de la década de $1850^{34}$. Vale decir, este $3 \%$ de impuesto era de alguna manera referencial, o una tasa máxima, lo importante para el gobierno era recaudar un máximo de $\$ 100.000$, distribuyendo las contribuciones entre provincias para llegar a esta cifra, incluso si eso implicaba que en lugar de 3\% la tasa a cobrar fuese inferior a dicho porcentaje ${ }^{35}$. Dicho guarismo, en cualquier caso, no alcanzaba a cubrir la totalidad del pago del capital e intereses del empréstito en Londres, pero al menos pagaba parte importante de ello, además de tranquilizar a los tenedores de bonos.

La tabla 1 resume la contribución del catastro a las arcas fiscales en el periodo bajo estudio. Desde su establecimiento, el catastro contribuyó alrededor de $2 \%$ de los ingre-

\footnotetext{
${ }^{30}$ Álvarez Correa, op. cit., pp. 3, 60-61, 70-72, 87-89, 102-103; José Ignacio González, "Primeros levantamientos cartográficos generales de Chile con base científica: los mapas de Claudio Gay y Amado Pissis", en Revista de Geografía Norte Grande, vol. 38, Santiago, 2007, pp. 21-44. De hecho, cabe destacar que el Conservador de Bienes Raíces se creó recién en 1857. Ernesto Greve, Don Amado Pissis y sus trabajos geográficos y geológicos en Chile, Santiago, Imprenta Universitaria, 1946.

${ }_{31}$ Ministerio del Interior, "Agrimensores", en Boletín de las leyes y de las ordenanzas y decretos del gobierno, libro 5, $\mathrm{N}^{\circ}$ 4, Santiago, 6 octubre de 1832, pp. 100-101.

${ }^{32}$ Chile, Principios elementales..., op. cit., p. 306. El impuesto debía ser pagado en octubre de cada año, ya sea por el propietario o por el agricultor arrendatario (los casos de arrendatarios de predios, sobre todo medianas y grandes propiedades, eran poco comunes en Chile durante este periodo). Ascención HernándezCastillo, Don Manuel Rengifo: sus doctrinas económicas y su actuación en el Ministerio de Hacienda, memoria de prueba para optar al título de Profesor de Estado, Santiago, Universidad de Chile, 1954.

${ }^{33}$ Cámara de Diputados, Acta de la sesión del 16 octubre 1834, en Chile, Sesiones de los Cuerpos Legislativos, Santiago, Imprenta Cervantes, 1835.

${ }^{34}$ El primer año de recaudación efectiva fue 1835, Memoria de Hacienda, Santiago, Imprenta Cervantes, 1835; Walpole a Palmerston. Santiago, noviembre 1834, en FO 132/2. Cabe destacar que la idea original de Rengifo era cobrarlo desde 1833, pero, finalmente, por cuestiones prácticas y presiones políticas, se optó por condonar los pagos de 1833 y 1834. Sesión de la Cámara de Diputados, 17 de octubre de 1834, en Chile, Sesiones de los Cuerpos..., op. cit., 1835. Entre 1835 y 1851 se recaudó en promedio poco menos de $\$ 70.000$ por año, bien distante de los $\$ 100.000$ propuestos.

${ }^{35}$ Ricardo Anguita, Leyes promulgadas en Chile desde 1810 hasta el 1 de junio de 1912, Santiago, 1912, vol. 1, pp. 229, 246-248; Manuel Montt, Mensaje sobre la reforma de la Contribución del Catastro, Santiago, Imprenta del Ferrocarril, 29 de agosto de 1856, pp. 1-2. En 1837 se dicta un nuevo cuerpo legal, complementario a los promulgados en 1831 y 1837, fijando el impuesto a pagar por cada propiedad antigua, o las que resultasen de subdivisiones, y que permaneció vigente hasta 1841, luego en 1842 y 1843 se confirman dichas tasas, hasta el catastro de 1852.
} 
sos fiscales totales de Chile, un porcentaje bajo dada la preeminencia de otras fuentes de ingreso fiscal, como los impuestos a la importación, en la estructura tributaria de este periodo. No obstante, la relevancia del catastro para nuestros propósitos en este artículo no reside en su aporte al Tesoro Nacional, sino en la riqueza de la información que proporciona para determinar con certeza las principales fortunas del sector agrario, así como la evolución de las mismas, en un lapso de más dos décadas.

\section{TABLA 1}

Participación porcentual de partidas dentro del ingreso fiscal de Chile

\begin{tabular}{|c|c|c|c|c|c|c|c|}
\hline Periodo & Diezmo & Estanco tabaco & Papel sellado & Catastro & Aduanas & Subtotal & Otras \\
\hline $1820-1829$ & $12 \%$ & $13 \%$ & $1,2 \%$ & $0,0 \%$ & $54 \%$ & $80 \%$ & $20 \%$ \\
\hline $1830-1839$ & $10 \%$ & $21 \%$ & $1,1 \%$ & $1,6 \%$ & $59 \%$ & $92 \%$ & $8 \%$ \\
\hline $1840-1849$ & $11 \%$ & $20 \%$ & $1,4 \%$ & $2,1 \%$ & $57 \%$ & $91 \%$ & $9 \%$ \\
\hline $1850-1859$ & $9 \%$ & $15 \%$ & $1,4 \%$ & $1,7 \%$ & $62 \%$ & $89 \%$ & $11 \%$ \\
\hline
\end{tabular}

Fuente: Elaboración propia sobre la base de datos de Elvira López, El proceso de construcción estatal en Chile. Hacienda pública y burocracia, 1817-1860, Santiago, Ediciones de la Dirección de Bibliotecas, Archivos y Museos, Centro de Investigaciones Diego Barros Arana, Colección Sociedad y Cultura, 2014, vol. LVIII, excepto cifras de diezmo para 1833-1839, cifras del estanco para 1821-1824 y cifras de papel sellado para 1834-1835 $5^{36}$. Chile, Memoria que el ministro de Estado en el Departamento de Hacienda presenta al Congreso Nacional, Santiago, Ministerio de Hacienda, 1834-1842; Chile, Resúmen de la Hacienda Pública de Chile: desde la independencia hasta 1900, Santiago, La Dirección, 1901.

(*) Para completar la serie hasta 1859, desde 1855 ingresamos, en su lugar, la contribución territorial.

En efecto, al catastrar los fundos del país, para cada predio con un ingreso anual (de mercado) igual o superior a $\$ 25$ por año, en los primeros dos catastros (1832-1834 y 1837-1838) se incluyó la siguiente información: provincia, parroquia, partido, nombre del predio, nombre del propietario, superficie (en cuadras), número de plantas de viña, ganado mayor, ganado menor, así como su renta anual (ingreso proveniente de ventas en el mercado). Lamentablemente, en el tercer catastro, de 1852, no se registraron las siguientes variables: superficie, plantas de viña, ganado mayor y ganado menor. Como contrapartida, en el primer catastro, 1832-1834, no solo se censaron los predios cuyos ingresos anuales de mercado fuesen iguales o superiores a $\$ 25$, sino que la totalidad de los fundos del país. Esto es, se realizó un completo censo del sector rural chileno. Con todo, considerando los tres censos, ingresamos información para casi cuarenta y cinco mil fundos, alcanzando alrededor de medio millón de registros (contabilizando cada uno como una celda de Excel). En suma, contamos con una base de datos de grandes proporciones, nunca antes analizada con programas estadísticos.

\footnotetext{
${ }^{36}$ Lamentablemente no hay información para el diezmo en 1831-1832, ni para papel sellado en 1831-1833 y 1836-1840. Al respecto, cabe destacar que la pobre calidad de los datos de recaudación fiscal para 18311833 se debe al caos administrativo que generó la guerra civil de 1831-1832. Walpole al Earl of Aberdeen. Santiago, 24 diciembre 1842, en FO 16/47.
} 


\title{
CARACTERIZACIÓN GENERAL DEL SECTOR AGRÍCOLA A TRAVÉS DEL CATASTRO
}

\author{
Y OTRAS FUENTES COMPLEMENTARIAS
}

A pesar de la falta de estudios monográficos sobre la agricultura chilena en el periodo considerado en este artículo, sabemos con certeza que era un sector muy poco desarrollado y en el que no se introdujeron las principales innovaciones técnicas ya aplicadas en la Europa industrializada ${ }^{37}$ e, incluso, en la Europa preindustrial y en algunas regiones avanzadas de Asia, especialmente China e India ${ }^{38}$. El sector agrario chileno estaba dominado por grandes haciendas caracterizadas por una baja productividad de la tierra y el trabajo, lo que era, incluso, reconocido por los propios agricultores. A principios de la década de 1840, El Agricultor, órgano oficial de la primera Sociedad de Agricultura ${ }^{39}$ (en adelante SA), llegó a sostener que "los propietarios de grandes haciendas suelen ser o demasiado vanos o muy ignorantes para que se quieran ocupar de las mejoras de sus posesiones" ${ }^{40}$. Observadores extranjeros también se sorprendían de la baja productividad del sector y de los arcaicos métodos de producción empleados todavía a mediados del siglo XIX, incluyendo a analistas autorizados, como el ingeniero italiano Luis Sada di Carlo, que visitó Chile en $1848^{41}$.

En efecto, las principales innovaciones tanto tecnológicas como organizacionales asociadas a la denominada "revolución agrícola" europea no fueron introducidas en Chile sino hacia el último tercio del siglo XIX. Francisco Xavier Rosales, encargado de negocios de Chile en Francia, luego de una breve residencia en dicho país no titubeó en aseverar:

“[...] la agricultura, puede decirse, se halla en Chile en la infancia [siendo] desconocidas las mejoras diarias que la agricultura [ha hecho] en Europa en el modo de trabajar la tierra, en los útiles de labranza que simplifican el trabajo, en el conocimiento de las estaciones, en la apreciación del mérito de las tierras para tal o tal cultura, en la elección de granos, su conservación y preservación de insectos; en la mejora de las razas de animales vacunos, caballares y lanares" $"$.

\footnotetext{
${ }^{37}$ Para este tema hay una amplia bibliografía. Para algunos buenos trabajos ilustrativos sobre el mismo, véase Tracy Dennison \& James Simpson, "Agriculture”, in Stephen Broadberry \& Kevin H. O’Rourke (eds.), The Cambridge Economic History of Modern Europe, Cambridge, Cambridge University Press, vol. 1: 17001870, 2010pp. 146-163; Mark Overton, Agricultural Revolution in England, Cambridge University Press, 1996; Karl Gunnar Persson, An Economic History of Europe. Knowledge, institutions and growth, 600 to the present, Cambridge, Cambridge University Press, 2010; Antonio Di Vittorio (ed.), An economic history of Europe, London, Routledge, 2006. Véase capítulos 4-6.

${ }^{38}$ Para desarrollos tempranos en el sector agrario chino e indio, véase, por ejemplo, Jack Goldstone, Why Europe? The rise of the West in World History, 1500-1850, New York, McGraw Hill, 2009.

${ }^{39} \mathrm{Su}$ nombre oficial fue Sociedad Chilena de Agricultura y Colonización, el que fue cambiado posteriormente a Sociedad de Agricultura y Beneficencia, y operó entre 1838 y 1848. Su primer presidente fue Domingo Eyzaguirre, su primer vicepresidente Pedro Nolasco Mena y su segundo vicepresidente Francisco García Huidobro. Como tesorero quedó Diego Antonio Barros y como secretario, Antonio García Reyes. La segunda Sociedad de Agricultura se refunda en 1856, pero de nuevo se disuelve luego de pocos años de operación.

${ }^{40}$ El Agricultor, $\mathrm{N}^{\circ} 29$, Santiago, enero 1843.

41 "Disertación Agrícola-Botánica", en El Agricultor, № 74, Santiago, enero 1848.

42 "Carta de J. X. Rosales a la SA", Burdeos, 26 diciembre de 1839, en El Agricultor, N 11, Santiago, junio 1840.
} 
Este lapidario diagnóstico no hacía referencia a la virtual inexistencia de mecanización agrícola, más bien asociada a la segunda mitad del siglo XIX y principios del Xx, sino a la persistencia de técnicas mucho más rudimentarias. Por ejemplo, en China, India, Inglaterra y los Países Bajos durante el periodo preindustrial se construyeron canales, puentes y caminos (antes del ferrocarril) para facilitar la circulación de mercancías agrícolas, así como obras complementarias para facilitar el riego. Adicionalmente, en esas agriculturas aumentó la intensidad en la rotación de cultivos (i.e. conversión de un sistema de tres campos a uno más intensivo de cuatro campos), incluyendo el empleo de trébol para alimentar animales, así como de nabos; se introdujo el encierro eficiente de animales (con buenos resultados para una mejor alimentación del ganado y fácil recolección de estiércol); se generalizó el uso de una variedad de abonos (estiércol, lejía y cal); se usaban herramientas de hierro de buena calidad (e.g. arados); y se introdujeron positivos cambios institucionales para aumentar la productividad en el largo plazo.

En contraste, considerando esas innovaciones, la situación de la agricultura chilena de la primera mitad del siglo XIX era muy distante de la de Europa del norte. Los redactores de El Agricultor coincidían durante los años 1830 y 1840 en un duro diagnóstico y en los casi ochenta volúmenes publicados entre 1838 y 1848 dieron cuenta, permanentemente, de la precariedad de las herramientas agrícolas usadas en Chile. Diego José Benavente, socio fundador de la SA, quizá exagerando, llegó a afirmar que los instrumentos de labranza a principios de la década de 1840 eran "casi los mismos que introdujeron nuestros padres con la conquista, y probablemente los que la necesidad enseñó a los primeros pobladores del mundo"43. Para El Agricultor, por ejemplo, respecto de elementos básicos como el arado "el hacendado chileno debería imitar al inglés en poner más esmero en el cultivo de las tierras, rompiéndolas y haciendo los surcos mucho más hondos... un arado inglés con dos yuntas de bueyes hace un trabajo igual a cuatro de los comunes del país [Chile], ¡y que trabajo tan distinto!" 44 . Este diagnóstico era corroborado por expertas visitas foráneas como el ya mencionado Luis Sada di Carlo ${ }^{45}$.

Respecto del uso de abonos, Chile también se encontraba muy atrasado en comparación con países como Inglaterra. El Agricultor aseveraba en 1839 que "hasta el día hemos descuidado en Chile esta parte tan interesante y necesaria del cultivo, contentándonos con lo que nuestras fértiles tierras producen por sí solas y sin necesidad de ayudar a la naturaleza por medio del abono"46. Además, persistía la creencia de que la cría de ganado era perjudicial para la producción agrícola, desconociendo la importancia de cultivos alternativos para alimentar el ganado y fertilizar la tierra, así como el uso de estiércol como abono. Por ello, la SA recomendaba a sus lectores medidas tales como abonar las tierras con cal, "sembrar nabos como preparación para una buena cosecha de trigo al año siguiente", el uso de lejía, como otra mejora "de las que se puede introducir

${ }^{43}$ El Agricultor, № 20, Santiago, diciembre 1841.

${ }^{44}$ Op. cit., $\mathrm{N}^{\circ} 11$, junio 1840 .

${ }^{45}$ Disertación Agrícola-Botánica, en El Agricultor, No 74, Santiago 1848. Cabe destacar que Luis Sada di Carlo fue posteriormente nombrado director de la Quinta Normal en Chile, obteniendo similar nombramiento años después en Perú.

${ }^{46}$ El Agricultor, $\mathrm{N}^{\circ}$ 6, Santiago, octubre 1839. 
en Chile con gran provecho" ${ }^{47}$, y el uso de heces animales como abono ${ }^{48}$. Más aún, tan tarde como 1846, El Agricultor reiteraba: "los abonos han de llevar la primera atención del labrador, quien por ningún motivo se ha de deshacer del heno, paja, rastrojo, raíces, y en suma de ninguna cosa que pueda convertirse en estiércol, sino que todo lo ha de emplear en los corrales para los ganados que tendrá en ellos"49.

Resulta también significativo destacar el escaso conocimiento que se tenía en nuestro país, antes de 1850, sobre la importancia de la rotación de cultivos y la improcedencia de dejar tierras sin cultivar ("barbechos"). Por ejemplo, en 1840 el comisario de Illapel reconocía sin ambigüedad alguna que en su localidad se seguía haciendo descansar los terrenos entre cosechas, en lugar de sembrar nabos o trébol ${ }^{50}$. Más duro aún era el diagnóstico de Domingo Arlegui, importante agricultor de Rancagua, quien sostuvo en 1843 que en Chile persistía la creencia generalizada de que la tierra,

"[...] a fuerza de producir se cansa, y que por consecuencia necesita de reposo [...] he aquí el principio que ha dado origen a los barbechos, pero es tan erróneo, que es conveniente demostrar su falsedad [...] y pasará mucho tiempo para generalizar la alternativa de cosecha [i.e. rotación de cultivos] tan recomendada por los agrónomos de Europa ${ }^{51}$.

En efecto, un agrónomo europeo se escandalizó al visitar Chile en 1848 y constatar un exceso de tierra sin cultivar y destinada a alimentar ganado, "condenando" a los animales a comer pastos de mala calidad, en lugar de usar parte de ella para producir forraje de calidad ${ }^{52}$. Para remediar ese problema, la SA proponía "que no se hagan seguidas dos cosechas de granos blancos, y que se entremetan con tino las que dejan mejorando el terreno para excusar los barbechos" ${ }^{\prime 3}$.

El estado de los caminos en Chile era otro obstáculo importante para el progreso del sector agrario. La precariedad de muchos caminos o la falta de ellos impedían el desarrollo de la producción de excedentes agrícolas para la exportación e, incluso, para parte del mercado doméstico. Dicha situación era bien resumida en 1840 por un redactor de El Agricultor:

"Échese la vista desde Copiapó hasta Valdivia, y búsquese en esta extensión inmensa cual es el pueblo que goza de una comunicación cómoda y expedita. Por todas partes vemos a nuestras pesadas carretas arrastrarse lentamente haciendo grandes rodeos o sumergiéndose en atolladeros de que parece no pudieran salir, para llegar a fuerza de tiempo y paciencia al punto en

\footnotetext{
${ }^{47}$ El Agricultor, $\mathrm{N}^{\circ}$ 11, Santiago, junio 1840.

${ }^{48}$ Op. cit., $\mathrm{N}^{\circ} 36$, agosto 1843.

${ }^{49} \mathrm{Op}$. cit., $\mathrm{N}^{\circ} 62$, octubre 1846 .

${ }^{50}$ Op. cit., $\mathrm{N}^{\circ} 14$, diciembre 1840 .

${ }^{51}$ Op. cit., $\mathrm{N}^{\circ} 36$, octubre 1843.

${ }^{52}$ Recomendaba además este visitante el encierre de animales para asegurarles una mejor alimentación. "Disertación Agrícola-Botánica", op. cit.

${ }^{53}$ El Agricultor, $\mathrm{N}^{\circ}$ 62, Santiago, octubre 1846. En uno de los últimos números de El Agricultor (N ${ }^{\circ} 74$, enero 1848), el redactor de dicha publicación seguía insistiendo que en Chile "no se practican los abonos que tanto benefician las tierras. Tampoco se hace con tino la alteración de cosechas por falta de nociones. Los instrumentos avanzados para la labranza y la jardinería tampoco se conocen".
} 
que deben deponer la carga... Los gastos en transporte suben [...] a una cantidad exorbitante con relación al valor de la especie [...] ¡Cuantas bellas ocasiones para hacer fortuna se pierden lastimosamente por este motivo" ${ }^{54}$.

En afinidad con lo anterior, en un extenso reporte sobre el estado de la agricultura en Chile a principios de la década de 1850, Stephen Sulivan, cónsul general británico en Chile, sentenció: "The bad State of the roads throughout the Republic is a great drawback to the agricultural interests of the country" 55 . De este modo, la producción agrícola chilena se limitaba principalmente al consumo interno local, más bien propio de economías maltusianas. No exageraba el mismo redactor de El Agricultor cuando escribió: "los caminos públicos desempeñan... las mismas funciones que los órganos en el cuerpo humano... [sin ellos] el cuerpo perecerá sin dudas" ${ }^{96}$. Y, de hecho, buena parte del atraso relativo del agro chileno bien podría explicarse por la falta de mercados de exportación: sin ellos los grandes agricultores no tenían mayores incentivos para realizar mejoras en los métodos de producción.

Consciente de la precaria situación de la agricultura chilena, uno de los principales objetivos de la Sociedad de Agricultura fue mejorar el cultivo de las tierras y la crianza de ganado, a través de la propagación de estudios y métodos prácticos conocidos de manera amplia en Europa ${ }^{57}$. Otros de sus objetivos fueron fomentar la construcción de buenos caminos ${ }^{58}$, puentes, canales ${ }^{59}$, y la introducción de sistemas de regadío, así como el uso de mejores semillas, razas animales y nuevas variedades de plantas. El impacto potencial de semejantes mejoras era inestimable. A modo de ejemplo, es ilustrativo el caso de Pedro José Pérez, un gran terrateniente del departamento de Casablanca. En 1831 inició la construcción de una represa para mejorar el riego en su hacienda Tapihue, concluyéndola en 1833 y habiendo realizado una inversión de $\$ 3.000^{60}$. Con la información que proporciona el catastro podemos confirmar que gracias a esta represa el ingreso anual de la hacienda se cuadriplicó en pocos años. De manera similar, los terrenos del Llano de Maipú, tasados en \$8 la cuadra, incrementaron su precio a \$100 la cuadra después de la introducción del regadío ${ }^{61}$.

${ }^{54}$ El Agricultor, $\mathrm{N}^{\circ}$ 12, Santiago, agosto 1840.

55 "Observations respecting the Agricultural Interests of the Republic of Chile as connected with the present state of Commerce”, Consul General Sulivan, 29 November 1852, in FO 16/79.

${ }^{56}$ El Agricultor, $\mathrm{N}^{\circ} 12$, Santiago, agosto 1840.

${ }^{57}$ Op. cit., $\mathrm{N}^{\circ} 1$, octubre 1838 .

${ }^{58} \mathrm{El}$ consejo de la SA estimaba que, respecto de este punto en particular, "se puede decir con fundamento que no se ha tocado ni tocará otro asunto que merezca con más justicia sus patrióticas tareas" en El Agricultor, $\mathrm{N}^{\circ} 12$, Santiago, agosto 1840 .

${ }^{59}$ La SA trató incluso de impulsar un canal entre Santiago y Valparaíso, un proyecto encargado a Andrés Antonio de Gorbea, pero finalmente desechado por los altos costos y complejidad asociada al mismo. El Agricultor, $\mathrm{N}^{\circ} 13$, Santiago, octubre $1840 \mathrm{y} \mathrm{N}^{\circ} 16$, abril 1841. Otros proyectos similares que se impulsaron desde la SA fueron los canales entre los ríos Claro y Lontué, que debían establecer una comunicación por agua hasta el puerto de Constitución; un canal para "unir el Ñuble con el Perquelauquén, cruzando de este modo la provincia del Maule en toda su extensión por un canal que facilite la exportación de los productos de la agricultura". El Agricultor, № 32, Santiago, abril 1843. Nótese el acento puesto en el mercado exportador.

${ }^{60}$ Op. cit., $\mathrm{N}^{\circ} 4$, abril 1839.

${ }^{61}$ Op. cit., $\mathrm{N}^{\circ}$ 51, noviembre 1844. 
Un importante factor que explica el pobre desarrollo del sector agrario chileno antes de 1850 eran las precarias condiciones laborales y de vida de los trabajadores rurales. Así, sus bajos salarios y bajo nivel de instrucción se traducían en una muy baja productividad. Para intentar paliar esta situación, la propia SA impulsó iniciativas para mejorar la situación de los trabajadores agrícolas, aunque con un marcado paternalismo. Entre ellas se cuenta la creación del Colegio de Artes y Oficios (en su nombre original, que sería la futura Escuela de Artes y Oficios) ${ }^{62}$, una escuela normal para niñas pobres, la Sociedad Benéfica de Señoras, entre otras medidas reformistas que poco ayudaban a resolver la desigualdad en la distribución del ingreso agrícola y los bajos ingresos del campesinado. En cualquier caso, en virtud de estos esfuerzos, a principios de la década de 1840 la Sociedad de Agricultura agregó a su nombre el acápite "y de Beneficencia", en reconocimiento a que "los campos son habitados por la miseria y la ignorancia; las clases pobres yacen en abandono" 63 .

Adicionalmente, la inexistencia de instituciones financieras, la consiguiente falta de capital y la ausencia de adecuados marcos legales regulatorios en nada ayudaban al sector $^{64}$. Como consecuencia, una buena parte de la tierra de las grandes haciendas permanecía sin ser explotada y el potencial exportador del sector no podía ser desarrollado. En contraste, la Europa contemporánea, en la que aumentaba el ingreso per capita, tenía un sólido sistema financiero en el que los agricultores podían disponer de capital; además, existían instituciones que daban seguridad a sus derechos de agua y de propiedad de la tierra, un uso generalizado de sistemas contables y de administración de grandes propiedades, capacidad de control de plagas y enfermedades, etc. Fue justo este tipo de desarrollos, que ocurrieron en algunos países europeos y asiáticos, pero no en la periferia del sistema mundo, los que dieron lugar a la denominada "pequeña divergencia" ${ }^{\circ}$.

Un obstáculo importante que merece una nota aparte fue la inexistencia de un sector financiero moderno que proveyera de capital para la inversión agrícola en Chile. Si bien este problema afectaba también al sector minero y al mercantil ${ }^{66}$, el lapso prolongado del ciclo agrícola entre la siembra y la comercialización de la producción, hacía al sector agrario en particular vulnerable a la inexistencia o escasez de financiamiento. Teniendo en cuenta la necesidad de contar con capital de trabajo para fomentar el progreso del sector, la SA abogó en forma permanente por la creación de un banco agrícola, siendo este "uno de los objetivos a los que debía con más ahínco dirigir su atención" Finalmente, cabe destacar que la SA fue también fundamental en la creación de la primera Caja de Ahorros de Chile, muy ligada a la promoción del ahorro por parte del campesinado.

\footnotetext{
${ }^{62}$ El Agricultor, $\mathrm{N}^{\circ}$ 34, Santiago, mayo 1843.

${ }^{63}$ Op. cit., $\mathrm{N}^{\circ}$ 51, noviembre 1844.

${ }^{64}$ En efecto, una de las cinco secciones de la primera SA se denominó "policía rural y legislación agrícola", op. cit., $\mathrm{N}^{\circ} 1$, octubre 1838 .

${ }^{65}$ Se refiere a la mejora en los niveles de vida de algunos países (e.g. Países Bajos, Inglaterra), y persistencia del estancamiento de dichos niveles en el resto del mundo, antes que comenzara la industrialización.

${ }^{66} \mathrm{Al}$ respecto, véase René Millar, Políticas y teorías monetarias en Chile, 1810-1925, Santiago, Universidad Gabriela Mistral, 1994, donde se destaca las implicancias de la falta de crédito, los elevados intereses y la escasez de circulante.

${ }^{67}$ El Agricultor, № 51, Santiago, octubre 1844.
} 
Las críticas respecto del pobre marco regulatorio del sector eran comunes. En 1841, por ejemplo, Antonio García Reyes, uno de los primeros secretarios de la SA, señalaba como problemas "la falta de leyes para conservar y reparar caminos, sobre distribución de aguas de riego, sobre protección de los derechos de los trabajadores" ${ }^{\prime 68}$. La SA fue insistente en la necesidad de una legislación sobre propiedad y acceso al agua proveniente de canales de regadíos ${ }^{69}$. En una memoria leída ante la SA, Rafael Larraín Moxó, uno de los diez agricultores más acaudalados de Chile para la totalidad del periodo bajo estudio (véanse tablas 6-8), y futuro vicepresidente de la SA, sostuvo: "entre nosotros no hay una ley, no hay un reglamento que determine como un individuo puede tomar posesión de las aguas de un río para cultivo u otro objeto"70. Ni siquiera para las aguas del río Mapocho estaban determinados con exactitud los derechos de propiedad de cada uno de sus regadores ${ }^{71}$. Esta situación, sin duda, atentaba contra el progreso de la agricultura chilena: la incertidumbre sobre derechos de propiedad no hace sino desincentivar la inversión y la innovación; por el contrario, un buen marco regulatorio y derechos de propiedad bien definidos son claves para promover nuevas inversiones ${ }^{72}$.

El panorama de atraso agrícola que hemos mostrado no quiere decir, naturalmente, que no hubiera producción agraria en Chile o que el sector no participara del boom del comercio mundial en productos primarios que comenzó con el fin de las guerras napoleónicas. En efecto, aun cuando la mayoría de la producción nacional se destinaba al consumo interno, muchos (grandes) agricultores chilenos también exportaban productos agrarios, principalmente trigo y harina (los que representaban más de la mitad de las exportaciones agrícolas de Chile durante nuestro periodo de interés) a regiones tan diversas como California, Australia, Brasil y el Río de la Plata, pero también otros productos como cebada, porotos, lana, charqui y cueros.

Una vez caracterizado a grandes rasgos el sector agrario chileno, y constatado su atraso, adquiere aún más relevancia examinar la composición de la élite agraria. Fundamentalmente, nos interesa establecer quiénes fueron los principales agricultores de la época, pues, en definitiva, fueron sus decisiones las que determinaron la trayectoria y situación del sector en el periodo bajo análisis. En ellos recayeron las decisiones respecto de introducir, o no, mejoras tecnológicas u organizacionales en el sector, y respecto de cuánto y cómo invertir. En concreto, queremos indagar en lo siguiente: ¿Cuántos fundos había en Chile? ¿Quiénes eran los más grandes agricultores? ¿Qué extensión tenían sus fundos? ¿Cuánto ganado y viñas concentraban los mismos? Estas preguntas son ahora posibles de responder, en esta y en la próxima sección, gracias a las bases de datos que hemos construido con la información cuantitativa contenida en los catastros.

${ }^{68}$ El Agricultor, $\mathrm{N}^{\circ} 20$, Santiago, diciembre 1841.

${ }^{69}$ Véase, para otro ejemplo, un discurso de Juan Manuel Cobos publicado en op. cit., $\mathrm{N}^{\circ} 42$, abril 1843.

${ }^{70}$ Op. cit., $\mathrm{N}^{\circ} 48$, agosto 1844 .

${ }^{71}$ Op. cit., $\mathrm{N}^{\circ} 38$, octubre 1843.

${ }^{72}$ El mismo Rafael Larraín Moxó añadió que aquel agricultor que quiera usar aguas para su fundo "debe ir preparado a sostener tantos pleitos como son los propietarios por cuyos terrenos atraviesa el cauce de la acequia que va a formar, a sufrir mil incomodidades y perjuicios, y expuesto a que después de conseguido su objeto el agua le sea robada, cuyo delito es, por desgracia, muy frecuente y rara vez castigado": op. cit., $\mathrm{N}^{\circ} 48$, agosto 1844 . 
TABLA 2

Número de predios agrícolas y población en Chile, 1813-1852

\begin{tabular}{|l|r|r|r|r|}
\hline \multicolumn{1}{|c|}{ Variable } & $\mathbf{1 8 1 3}\left(^{*}\right)$ & $\mathbf{1 8 3 2 - 1 8 3 4}$ & $\mathbf{1 8 3 7 - 1 8 3 8}$ & $\mathbf{1 8 5 2}$ \\
\hline Número de fundos totales de Chile & 15.000 & 21.915 & c. 25.000 & c. 37.000 \\
\hline Número de fundos que pagaban catastro & 0 & 5.408 & 9.977 & 33.040 \\
\hline Población chilena $\left(^{* *}\right)$ & 846.166 & 1.080 .554 & 1.172 .914 & 1.487 .451 \\
\hline Porcentaje de familias rurales que no poseían tierra & ND & $86 \%$ & ND & ND \\
\hline $\begin{array}{l}\text { Porcentaje de familias rurales que no poseía tierra } \\
\text { que pagaba catastro }\end{array}$ & ND & $97 \%$ & $94 \%$ & $86 \%$ \\
\hline
\end{tabular}

Fuente: Para fundos, elaboración propia sobre la base de ANCH-FDGE y Chile, Estado que..., op. cit. Los datos de población fueron tomados de Díaz, Lüders y Wagner, op. cit. (*) Estimado sobre la base del censo de 1813, que arroja once mil predios, excluidos Concepción y parte de Santiago. Se agregaron otros cuatro mil en función de la participación de estas localidades en el total de fundos del catastro de 1832-1834. $\left(^{* *}\right)$ En la tercera columna se consideró la población de 1832 y en la cuarta la de 1837.

El primer censo agrícola de la República arrojó que existían en Chile casi veintidós mil predios agrícolas, de los cuales unos cinco mil cuatrocientos pagaban el catastro (tabla 2). A su vez, de acuerdo con el primer censo de población, hacia 1813 habría unos quince mil predios en todo Chile. Esto es, entre la independencia y comienzos de la década de 1830 el número de predios aumentó de forma significativa, en casi 50\%. Los catastros de 1837-1838 no registraron todos los fundos, sino solo aquellos que pagaban el impuesto, pero sí sabemos que en 1837-1838 casi diez mil fundos pagaban el catastro y que en 1852 lo hacían más de treinta y tres mil. Es decir, a principios de la década de 1850 ya había en Chile con toda certeza más de treinta y tres mil fundos, en total quizá del orden de los treinta y siete mil, casi triplicando el número de predios agrícolas al momento de la independencia. Estas cifras dan cuenta de un importante proceso de subdivisión de la propiedad agrícola en Chile (toda vez que el territorio nacional no sufrió modificaciones durante este periodo $)^{73}$, que se explica fundamentalmente por una clara política de gobierno para tales efectos. Desde inicios de la década de 1830 el gobierno promovió la subdivisión de grandes propiedades. Para ello se abolieron los impuestos a la compra-venta de pequeñas y medianas propiedades; se modificó el sistema de herencias en la Constitución de 1833 para favorecer a todos los hijos, no solo al mayor; en esta misma línea, se abolió la institución del mayorazgo ${ }^{74} \mathrm{y}$, como sabemos, se eximió del pago del catastro a aquellos fundos que producían menos de $\$ 25$ al año de productos destinados al mercado ${ }^{75}$.

${ }^{73}$ Tan potente fue este proceso de partición de tierras, que se estimaba que a principios de la década de 1830 la mitad de las disputas judiciales en Chile eran por esta causa. Álvarez Correa, op. cit., p. 88.

${ }^{74} \mathrm{Al}$ respecto, cabe citar la tesis doctoral de Álvarez Correa, op. cit., p. 104: "la abolición de los mayorazgos, es decir, el mantenimiento de una propiedad en una familia y que pasara íntegramente a manos del hijo mayor, trajo consigo, una fuerte subdivisión de propiedades" en Chile. Véase también Mensajero Agrícola, enero 1857. Para cuerpos legales, véase Código Civil de Chile, Madrid, Instituto de la Cultura Hispánica, 1961 [1857].

${ }^{75}$ Vicuña Mackenna, op. cit., p. 77; Domingo Amunátegui, Estudios históricos, Santiago, Universidad de Chile, 1940, pp. 88-91; Claudio Gay, Historia física y política de Chile, Santiago, Cámara Chilena de la Construcción, Pontificia Universidad Católica de Chile y Biblioteca Nacional de Chile, 2009, tomo II, pp. 63-67. 
No obstante, de las cifras disponibles en la tabla 2 queda claro que un altísimo porcentaje de la población rural no poseía tierra, otra manifestación evidente del atraso en que se encontraba el agro chileno. Nuestras estimaciones indican que en 1832-1834, un $86 \%$ de las familias del sector rural no poseía tierra. Sociedades más avanzadas que la chilena, como las de Estados Unidos o Inglaterra, se caracterizaban por tener una mejor distribución de la tierra, lo que les asegura una mejor distribución del ingreso y, por tanto, un mayor poder adquisitivo en un mayor rango de la población, lo cual es clave para aumentar el consumo interno y, por consiguiente, la producción. En suma, mientras mayor sea el mercado objetivo potencial, mayores son los incentivos que tienen los empresarios para invertir en mejoras productivas. La única región de América Latina para la que existen datos comparables es la campaña de Buenos Aires. De acuerdo con Jorge Gelman y Daniel Santilli ${ }^{76}$, al menos un 38\% de las familias en ese territorio en 1839 poseían propiedades rurales, muy por encima del 14\% que se observa para Chile en 1832 (y que no debe ser muy distinto de lo ocurrido en 1837-1838) ${ }^{77}$.

Respecto del stock del ganado, el catastro nacional de 1832-1834 (tabla 2) registró seiscientas treinta y seis mil cabezas de ganado mayor (vacas, toros, bueyes, mulas, caballos y yeguas) y ochocientas cincuenta y un mil cabezas de ganado menor (ovejas y cabras) para la totalidad de los predios de la República. Esta es la primera estimación precisa del stock total de ganado total de Chile para el periodo estudiado. De esta masa ganadera, quinientas sesenta mil (88\%) y quinientas ochenta mil (68\%), respectivamente, se encontraban en fundos que pagaban el catastro, lo que sugiere que los pequeños agricultores que no pagaban catastro eran más propensos a tener ganado menor por sobre el mayor. En relación con cifras disponibles para periodos anteriores a la década de 1830, en 1806 el ganado de Chile se estimaba en alrededor de un millón de cabezas de mayor e igual número para el menor ${ }^{78}$, lo que, de ser correcto, implica que el stock de ganado en 1832 era menor que al momento de la Independencia (lo que podría explicarse por la destrucción asociada a las guerras, que tanto afectó al sector rural).

\footnotetext{
${ }^{76}$ Gelman y Santilli, De Rivadavia a Rosas..., op. cit., p. 55.

${ }^{77}$ Información cualitativa para otras regiones muestra una situación similar: la mayoría de la población no poseía propiedades rurales, aun cuando la mayoría de la población vivía en el campo. Para el caso de Ecuador, véase Brooke Larson, Trials of Nation Making: Liberalism, Race, and Ethnicity in the Andes, 1810-1910, Cambridge, Cambridge University Press, 2004. Para el caso peruano, véase Jean Piel, El capitalismo agrario en el Perú, Salta, Universidad Nacional de Salta, 1995 y para el uruguayo véase María Inés Moraes y Raquel Pollero, "Categorías ocupacionales y estatus en una economía de orientación pastoril: Uruguay en la primera mitad del siglo xix" en Tarcísio R. Botelho y Marco H. D. Van Leeuwen, Mobilidade social na América Latina em perspectiva histórica, Belo Horizonte, Editora da PUC Minas, 2010, pp. 103-148.

${ }^{78}$ El Agricultor, $\mathrm{N}^{\circ} 36$, Santiago, agosto 1843.
} 
TABLA 3

Ingreso anual, superficie, plantas de viña y ganado del agro chileno, 1832-1838

\begin{tabular}{|l|c|c|c|c|}
\hline \multirow{2}{*}{\multicolumn{1}{|c|}{ Variable }} & Total & \multicolumn{3}{c|}{ Solo que pagaban el catastro } \\
\cline { 2 - 5 } & $1832-1834$ & $1832-1834$ & $1837-1838$ & 1852 \\
\hline Hectáreas de tierras (millones) & 3,1 & 2,5 & 3,2 & $\mathrm{ND}$ \\
\hline Ingreso anual de los fundos (\$ millones) & 1,64 & 1,52 & 2,76 & 7,40 \\
\hline Plantas de viña (millones) & 19,8 & 15,6 & 25,0 & $\mathrm{ND}$ \\
\hline Ganado mayor (miles) & 636 & 560 & 782 & $\mathrm{ND}$ \\
\hline Ganado menor (miles) & 851 & 580 & 943 & $\mathrm{ND}$ \\
\hline
\end{tabular}

Fuente: Elaboración propia sobre la base de ANCH-FDGE; Chile, Estado que..., op. cit.

Para 1837-1838, como ya se mencionó, el censo agrícola incluyó solo los fundos que pagaban catastro, por lo que tenemos a nuestra disposición solo las cabezas de ganado existentes en dichos predios, registrándose 782.000 cabezas de ganado mayor y 943.000 de ganado menor (tabla 3). Estimaciones para el total de Chile c.1840, cercanas, por tanto, a 1838, arrojan un millón de cabezas de ganado mayor ${ }^{79}$. Si estas cifras son correctas, los datos del catastro sugieren que los propietarios que pagaban el catastro seguían concentrando buena parte del ganado mayor, tal como vimos para 1832-1834. Llegado este punto parece necesario poner dichas cifras en un contexto comparativo, por ejemplo: ¿Cómo se comparan estas cifras de ganado con otros países de la región? Nuevamente, solo disponemos de cifras para la campaña de Buenos Aires en 1839. Para ese territorio, que congregaba poco más de 150.000 habitantes, Jorge Gelman y Daniel Santilli ${ }^{80}$ reportan 3.600.000 de cabezas de ganado mayor y 2.300.000 de cabezas de ganado menor, muy por encima de las cifras totales para Chile, que tenía una población seis veces mayor que la de la campaña de Buenos Aires ${ }^{81}$. En términos per capita, los habitantes de esta región poseían alrededor de veinte veces más ganado que los chilenos, pero también es cierto que durante este periodo las haciendas chilenas eran más bien complejos multiproductivos (e.g. ganaderos, cerealeros, vitivinícolas), mientras que las estancias bonaerenses se caracterizaban por una concentración en actividades ganaderas.

\footnotetext{
${ }^{79}$ Vicuña Mackenna, op. cit.

${ }^{80}$ Gelman y Santilli, De Rivadavia a Rosas..., op. cit., p. 52.

${ }^{81}$ Para Uruguay, alrededor de 1850 se estima que había dos millones de cabezas de ganado mayor y unas ochocientas mil cabezas de ganado menor: Moraes y Pollero, op. cit.
} 
TABLA 4

Cabezas de ganado mayor y menor por provincia en Chile, 1832-1838

\begin{tabular}{|l|r|r|r|r|r|r|r|r|r|r|}
\hline \multicolumn{1}{|c|}{ Provincia } & \multicolumn{2}{|c|}{ Total } & \multicolumn{6}{c|}{ Solo en los fundos que pagaban el catastro } \\
\hline & \multicolumn{1}{|c|}{$1832-1834$} & \multicolumn{1}{c|}{$1832-1834$} & \multicolumn{2}{c|}{$1837-1838$} & \multicolumn{2}{c|}{$1832-1834$} & \multicolumn{2}{c|}{$1837-1838$} \\
\hline & $\begin{array}{c}\text { Ganado } \\
\text { mayor }\end{array}$ & $\begin{array}{c}\text { Ganado } \\
\text { menor }\end{array}$ & $\begin{array}{c}\text { Ganado } \\
\text { mayor }\end{array}$ & $\begin{array}{c}\text { Ganado } \\
\text { menor }\end{array}$ & $\begin{array}{c}\text { Ganado } \\
\text { mayor }\end{array}$ & $\begin{array}{c}\text { Ganado } \\
\text { menor }\end{array}$ & $\begin{array}{c}\text { Ganado } \\
\text { mayor }\end{array}$ & $\begin{array}{r}\text { Ganado } \\
\text { menor }\end{array}$ & $\begin{array}{c}\text { Ganado } \\
\text { mayor }\end{array}$ & $\begin{array}{c}\text { Ganado } \\
\text { menor }\end{array}$ \\
\hline Coquimbo-Serena & 41.766 & 28.814 & 28.107 & 25.582 & 47.128 & 47.321 & $5 \%$ & $4 \%$ & $6 \%$ & $5 \%$ \\
\hline Aconcagua & 67.268 & 51.052 & 60.908 & 46.630 & 75.214 & 65.793 & $11 \%$ & $8 \%$ & $10 \%$ & $7 \%$ \\
\hline Santiago & 268.672 & 124.531 & 261.060 & 117.130 & 298.846 & 179.700 & $47 \%$ & $20 \%$ & $38 \%$ & $19 \%$ \\
\hline Colchagua & 135.263 & 135.278 & 125.139 & 101.614 & 174.781 & 197.098 & $22 \%$ & $18 \%$ & $22 \%$ & $21 \%$ \\
\hline Talca & & & & & 42.795 & 67.156 & $0 \%$ & $0 \%$ & $5 \%$ & $7 \%$ \\
\hline Maule & 73.815 & 252.814 & 56.435 & 181.206 & 45.972 & 186.093 & $10 \%$ & $31 \%$ & $6 \%$ & $20 \%$ \\
\hline Concepción & 29.719 & 147.766 & 19.026 & 103.170 & 79.461 & 184.689 & $3 \%$ & $18 \%$ & $10 \%$ & $20 \%$ \\
\hline Chiloé & 4.996 & 99.278 & 16 & 163 & 2.666 & 5.590 & $0 \%$ & $0 \%$ & $0 \%$ & $1 \%$ \\
\hline Valdivia & 14.566 & 11.645 & 9.202 & 4.570 & 14.690 & 9.559 & $2 \%$ & $1 \%$ & $2 \%$ & $1 \%$ \\
\hline Total & 636.065 & 851.178 & 559.893 & 580.065 & 781.553 & 942.999 & $100 \%$ & $100 \%$ & $100 \%$ & $100 \%$ \\
\hline
\end{tabular}

Fuente: Elaboración propia sobre la base de ANCH-FDGE.

Al desagregar los datos por provincias (tabla 4), podemos constatar que Santiago concentraba el ganado mayor, seguida por Colchagua. En los dos primeros censos ambas provincias agrupaban el $69 \%$ y $60 \%$, respectivamente, del total de ganado mayor de Chile. El ganado menor, en cambio, se repartía de manera más proporcionada, algo concordante con lo ya señalado en el sentido de que pequeños propietarios eran más proclives a criar cabras y ovejas en lugar de vacas, por ejemplo, seguramente debido al menor costo de adquisición del ganado menor ${ }^{82}$. En 1832-1834 la provincia del Maule lideraba en cuanto a cabezas (con un $31 \%$ de participación entre los fundos que pagaban catastro), pero en 1837-1838 la participación de Colchagua, Concepción, Maule y Santiago era bastante similar, en torno al 19-21\% del total de cabezas de ganado menor para cada provincia.

Respecto del número de plantas de viña, el censo de 1832-1834 registró casi veinte millones de plantas para la totalidad de la República. De estas, 15.500.000 se encontraban en fundos que pagaban el catastro, una cifra que sube a veinticinco millones de plantas en 1837-1838. En consecuencia, es probable que entre 1832 y 1838 el total de vides haya aumentado en casi un 50\%, llegando a unas treinta millones de plantas. Desagregando estos datos por provincias, es posible concluir que Concepción era por lejos la que concentraba la mayor cantidad de viñedos en Chile, seguida por Maule y Santiago (tabla 5) ${ }^{83}$. En con-

${ }^{82}$ Por ejemplo, el precio de una vaca en el Chile de la década de 1830 oscilaba entre los $\$ 12$ y los $\$ 16$ cada una, mientras que una oveja podía llegar a costar $\$ 1$, incluso siete reales. Esto es, una vaca podía llegar a costar unas quince veces más que una oveja. Información extraída de ANCH-Contaduría Mayor, vol. 464, 480 y 481 .

${ }^{83}$ Complementando la evidencia con información de otras fuentes, de acuerdo con las estimaciones de Fernando Urizar, en 1844 había unos ocho millones de plantas de viña en la provincia del Maule, la única provincia para la que podemos hacer comparaciones con otras fuentes fidedignas. Nuestros datos para 18371838 arrojan cuatro millones de plantas en fundos que pagaban catastro, pero de la información de 1832 sabemos que del total de plantas en todo el Maule, un $72 \%$ se encontraba en fundos que pagaban catastro. 
junto, la información de las tablas anteriores proporciona una aproximación adecuadamente fundada de la extensión, magnitud y del total de la riqueza del agro chileno entre 1832 y 1852. Sin embargo, una omisión importante es la ausencia de información directa sobre cultivo de trigo, producción de harina y otros productos, como fruta fresca, legumbres y cebada. Así, siendo el trigo el principal cultivo en Chile, resulta sorprendente que las juntas catastrales no consignaran la superficie cultivada con este cereal. En la siguiente sección procederemos a analizar cómo se distribuía la riqueza del sector agrícola chileno, $\mathrm{y}$, en especial, quiénes eran los principales miembros de la clase terrateniente chilena.

TABLA 5

Plantas de viña por provincia en Chile, 1832-1838

\begin{tabular}{|l|r|r|r|r|c|}
\hline \multicolumn{1}{|c|}{ Provincia } & Total & \multicolumn{3}{c|}{ Solo en los fundos que pagaban el catastro } \\
\hline & $1832-1834$ & $1832-1834$ & $1837-1838$ & $1832-1834$ & $1837-1838$ \\
\hline Coquimbo-Serena & 1.063 .023 & 942.482 & 983.388 & $6 \%$ & $4 \%$ \\
\hline Aconcagua & 1.397 .107 & 1.341 .875 & 1.556 .915 & $9 \%$ & $6 \%$ \\
\hline Santiago & 2.600 .416 & 2.475 .628 & 3.260 .031 & $16 \%$ & $13 \%$ \\
\hline Colchagua & 740.566 & 637.400 & 902.453 & $4 \%$ & $4 \%$ \\
\hline Talca & & & 486.550 & $0 \%$ & $2 \%$ \\
\hline Maule & 4.409 .859 & 3.186 .180 & 4.011 .378 & $20 \%$ & $16 \%$ \\
\hline Concepción & 9.577 .940 & 7.014 .785 & 13.806 .605 & $45 \%$ & $55 \%$ \\
\hline Chiloé & 160 & & 2.800 & $0 \%$ & $0 \%$ \\
\hline Total & 19.789 .071 & 15.598 .350 & 25.010 .120 & $100 \%$ & $100 \%$ \\
\hline
\end{tabular}

Fuente: Elaboración propia sobre la base de ANCH-FDGE.

\section{PRINCIPALES FORTUNAS DEL SECTOR AGRíCOLA CHILENO,}

\section{$1832-1852$}

Como indicamos en la Introducción, examinar la composición de la élite agraria es una de las contribuciones que se puede hacer a través del análisis de los sucesivos catastros. En esta sección identificaremos las principales fortunas agrícolas y examinaremos en qué medida se registró una transformación en el núcleo superior de la élite agraria antes de 1852, fecha del tercer catastro considerado en este trabajo. Previamente, para efectos comparativos, es de interés destacar las principales fortunas chilenas antes de

Si estas proporciones se mantienen en 1837-1838, el total estimado para todo el Maule no sería de cuatro millones sino de 5.500.000 en 1837-1838. Luego, sabemos, también, que entre 1832 y 1838 , el total de plantas en el Maule en fundos que pagaban catastro subió en un $25 \%$ aproximadamente. Si esta tasa de crecimiento se hubiese mantenido entre 1838 y 1844 llegaríamos a casi siete millones de plantas, muy cerca de los ocho millones estimados por Fernando Urizar, lo que da mayor validez a nuestras cifras del catastro. Fernando Urízar, Estadística de la República de Chile: provincia del Maule, Santiago, Imprenta de Los Tribunales, 1845 , tomo I. 
la Independencia. Un listado de los "magnates" del Santiago de principios de la década de 1790 (que excluye fortunas fuera de la capital, la cual, no obstante, concentraba buena parte de la riqueza total de la capitanía), ${ }^{84}$ confeccionado por la expedición de Alejandro Malaspina, ${ }^{85}$ y dado a conocer por Ricardo Couyoumdjian ${ }^{86}$, indica que había unos treinta y cinco "magnates" con una renta superior a los $\$ 25.000$. La renta de siete de ellos sobrepasaba los $\$ 100.000$, a saber: el conde de la Conquista, marqués de Casa Real, marqués de Villa Palma, Pedro Balmaceda, José Ramírez, Antonio Labra y José Antonio Alcalde. Con una renta de \$100.000 figuraban ocho grandes terratenientes: Agustín Tagle, Francisco de Bezanilla, Salvador Trucíos, Juan Francisco Lavaqui, Pedro Antonio del Villar, Ignacio Irigaray, Celedonio Villota y Felipe Zaldívar. Luego figuraban otros cuatro "magnates" con rentas en torno a \$80.000: Roque Huisi, Francisco Javier Urmeneta; Eugenio Valero y Pedro Palazuelos. Finalizan el listado diecisiete "magnates" con rentas de entre $\$ 25.000$ y $\$ 50.000$. En total, la renta estimada de estos treinta y seis sujetos superaba con creces los $\$ 2.300 .000^{87}$.

De estos treinta y seis "magnates" de fines de la Colonia, por razones obvias (i.e. apoyaban el bando realista), uno esperaría que muchos de ellos dejaran el país con la consolidación de la Independencia, llevándose con ellos sus capitales. No obstante, resulta interesante destacar que buena parte de ellos, o sus hijos, permanecieron ligados a la élite terrateniente y política chilena posindependencia, como veremos más adelante, y que hemos identificado con los catastros. Los casos más llamativos, por pertenecer a los top 7 magnates del Santiago de fines de la Colonia, son (se indica entre paréntesis su descendiente que figura entre los agricultores de mayor ingreso en nuestros rankings de 1832-1852): el conde de la Conquista (Juan de Dios Correa); marqués de Villa Palma (Martín Calvo Encalada); José Antonio Alcalde (Juan Agustín Alcalde); marqués de Casa Real (Vicente Huidobro y José Antonio Valdés). Otros casos, no incluidos en la lista de Alejandro Malaspina, pertenecientes a la élite colonial, y que figuran en algunos de nuestros rankings del decenio 1830 como grandes terratenientes son (entre paréntesis el nombre del personaje incluido en nuestros listados): Marquesado de Cañada (Ana Josefa de Azúa y Marín, heredó el título de marquesa por sucesión de sus hermanos); marquesado de Montepío (Francisco Ramón Vicuña, casado con Mariana Aguirre Boza, hija de los marqueses de Montepío); mayorazgo Ruiz Tagle (Manuel Ruiz Tagle); y mayorazgo Herrera y Rojas (Bárbara Molina y Agüero esposa de Miguel Herrera y Rojas, y Bárbara Rojas, hija de ambos).

Para complementar nuestra evidencia con fuentes secundarias, podemos considerar que en su conocido artículo sobre élites en Chile durante el siglo XVIII ${ }^{88}$, Jacques Barbier

\footnotetext{
${ }^{84}$ Alberto Edwards, La Fronda Aristocrática en Chile, Santiago, Imprenta Nacional, 1928, pp. 12-16.

${ }^{85}$ Sobre dicha expedición, véase Rafael Sagredo Baeza y José Ignacio González Leiva, La Expedición Malaspina en la frontera austral del imperio español, Santiago, Editorial Universitaria, 2004.

${ }^{86}$ Ricardo Couyoumdjian, "Los magnates chilenos del siglo Xvin", en Revista Chilena de Historia y Geografia, $\mathrm{N}^{\circ} 136$, Santiago, 1968, pp. 315-322.

${ }^{87}$ Para que el lector se haga una idea, el valor del oro y plata acuñado por año en Chile a principios de la década de 1790 no superaba el $\$ 1.000 .000$ anual; el ingreso fiscal de todas las cajas de Chile en 1790 fue de $\$ 1.800 .000$, mientras que el valor total de las exportaciones chilenas en el decenio 1790 no superaba los $\$ 2.200 .000$ por año.

${ }^{88}$ Jacques A. Barbier, "Elite and cadres in Bourbon Chile", in Hispanic American Historical Review, vol. 52, N 3, Durham, 1972, pp. 416-435. Sobre las élites de este periodo, véase también los siguientes trabajos:
} 
listó todas las familias que adquirieron títulos de Castilla o mayorazgos en el siglo XVIII en Santiago de Chile. Estas eran: Irarrázabal, Mesía, Marín de Poveda, Ruiz de Azúa, Cerda, Calvo Encalada, Larraín, Aguirre, Caldera, García Huidobro, Alcalde, Valdés, Lecaros, Toro Zambrano, Fernández de Balmaceda, Rojas, Rojas de Larraín, Ruiz Tagle, Prado y Herrera. De estas veinte familias, más de la mitad (doce) se repiten dentro de las familias que figuran en nuestros reducidos listados de los cuarenta y ocho propietarios más acaudalados del agro chileno entre 1832 y 1852 . La persistencia de más del $60 \%$ de las familias que componían la élite nacional entre el último siglo de la era colonial ("vieja elite colonial") y las primeras décadas de Chile independiente es incuestionable. Se observa, además, una persistencia notoria en la desigualdad de la riqueza y del ingreso en este periodo puente entre la Colonia y la "primera globalización" (c. 1870-1913).

En efecto, nuestros propios cálculos muestran que entre 1832 y 1852 existía una gran desigualdad en la distribución del ingreso y de la tierra en el sector agrícola chileno. Para ello hemos usado diversos indicadores de desigualdad, agrupando los fundos de acuerdo con cada propietario. Entre dichos indicadores cabe destacar que el Coeficiente Gini ${ }^{89}$ del ingreso agrícola entre los propietarios que pagaban el catastro fue de $0.75,0.75$ y 0.79 para $1832-1834,1837-1838$ y 1852 , respectivamente; es decir, un valor bastante alto. También se encontró que para 1832-1834, el único censo para el cual se dispone del total de propietarios (no solo aquellos que pagaban el catastro), el Coeficiente Gini del ingreso agrícola era de 0.897, extraordinariamente alto. Estas cifras dan cuenta de un fenómeno relativamente conocido, pero que ahora por vez primera podemos cuantificar con precisión.

Respecto de la desigualdad en la distribución de la tierra (no del ingreso), encontramos que el Coeficiente Gini de la distribución de la tierra fue de 0.92 en 1832-1834 si todos los propietarios son considerados, y 0.87 para el mismo periodo si solo se incluye los propietarios que pagan el catastro; en ambos casos, el indicador es muy alto. Respecto de este último grupo (propietarios que pagan catastro), para 1837-1838 el coeficiente de la tenencia de la tierra fue de 0.86. Finalmente, se estimó el porcentaje de hogares agrícolas que no poseían tierra, y para 1832-1834 dicho ratio es de 86\%, extraordinariamente alto también. Para 1837-1838 y 1852 no hay estimaciones para el total de la población rural, pero sí podemos determinar que el porcentaje de los hogares rurales que no poseía tierra que generaba un ingreso de mercado de \$25 o más al año era de $97 \%$, $94 \%$ y $86 \%$ para $1832-1834,1837-1838$ y 1852 , respectivamente (tabla 2 ). Al respecto, cabe poner estos $\$ 25$ en contexto. Según datos provistos por Claudio Gay, alrededor de 1840 un peón agrícola ganaba un salario nominal de \$40-\$45 anuales, además de la comida. Por su parte, calculaba el consumo de productos agrícolas de una familia de agri-

Edwards, op. cit.; Domingo Amunátegui Solar, La sociedad chilena del siglo XVIII: mayorazgos y titulos de Castilla, Santiago, Encuadernación Barcelona, 1901-1904; entre otros.

${ }^{89}$ El Coeficiente Gini es una medida de desigualdad de cualquier variable, aunque normalmente se usa para medir desigualdad de ingreso y de riqueza. En concreto, es un número entre 0 y 1 . Mientras más cercano a 0 es su valor, mayor es la igualdad de la variable que se mide. A su vez, mientras más cercano a 1 es su valor, mayor la desigualdad. 
cultores compuesta por seis personas en $\$ 64$ y un gasto de $\$ 20$ anuales en vestimenta ${ }^{90}$. Vale decir, un altísimo porcentaje de la población rural no poseía tierra o los predios de su propiedad generaban excedentes muy bajos.

Otro ejercicio que realizamos fue analizar en detalle tanto los fundos más rentables como los más grandes de Chile en el periodo estudiado. Para ello hemos seleccionado a los primeros cuarenta y ocho terratenientes de todos los propietarios que generaban mayor ingreso anual en los censos realizados entre 1832 y $1852^{91}$. La tabla 6 contiene el ingreso anual estimado de los cuarenta y ocho mayores propietarios para el censo agrícola de 1832-1834, que juntos concentraban un 22\% del ingreso total de los fundos que pagaban el catastro, que además concentraban más de un tercio del ganado mayor, un $9 \%$ del ganado menor y más de un sexto de toda la tierra. La lista es encabezada por Fernando Errázuriz, con un ingreso anual de \$18.000, procedente de cuatro fundos, todos localizados en Santiago, y que en total sumaban casi 16.000 ha, 129.000 plantas de viña, 7.900 cabezas de ganado mayor y 1.600 cabezas de ganado menor. El segundo en la lista, de acuerdo con ingreso agrícola anual, era José Antonio Valdés, también poseedor de cuatro fundos, que totalizaban algo más de 14.000 ha, 24.000 plantas de viña, 9.200 cabezas de ganado mayor y 700 de ganado menor.

Por su parte, José Nicolás de la Cerda era propietario de seis fundos, todos en La Ligua, provincia de Aconcagua, que generaban un ingreso anual estimado de $\$ 16.300$. A diferencia de Fernando Errázuriz y José Antonio Valdés, se dedicaba principalmente a la ganadería, actividad en la que empleaba más tierra que los dos primeros. En efecto, era poseedor de casi 23.000 ha, 11.300 y 1.600 cabezas de ganado mayor y menor, respectivamente. El cuarto lugar en el ranking de ingresos agrícolas correspondía a Juan de Dios Correa, dueño de solo dos fundos en la provincia de Santiago, pero que en conjunto abarcaban casi 19.000 ha, 16.000 plantas de viña, 12.000 y 1.000 cabezas de ganado mayor y menor respectivamente, siendo el principal poseedor de cabezas de ganado mayor de todo el país. Con el mismo nivel de ingreso anual figuraba Francisco Tagle, poseedor de fundos por casi 13.000 ha, 25.000 plantas de viña, 8.000 y 800 cabezas de ganado mayor y menor, respectivamente.

TABLA 6

Ingreso anual agrícola del 1\% más rico (según ingresos) de los propietarios de predios agricolas chilenos, 1832-1834

\begin{tabular}{|r|l|c|r|r|r|c|}
\hline \multicolumn{1}{|c|}{$\mathbf{N}^{\mathbf{0}}$} & \multicolumn{1}{|c|}{ Propietario } & $\begin{array}{c}\text { Ingreso anual } \\
\text { de sus fundos }\end{array}$ & $\begin{array}{c}\text { Ganado } \\
\text { Mayor }\end{array}$ & $\begin{array}{c}\text { Ganado } \\
\text { Menor }\end{array}$ & $\begin{array}{c}\text { Plantas } \\
\text { de Viña }\end{array}$ & $\begin{array}{c}\text { Hectáreas } \\
\text { de sus fundos }\end{array}$ \\
\hline 1 & Errázuriz, Fernando & 18.000 & 7.900 & 1.600 & 129.000 & 15.857 \\
\hline 2 & Valdez, José Antonio & 17.320 & 9.160 & 700 & 24.000 & 14.177 \\
\hline 3 & De la Cerda, José Nicolás & 16.300 & 11.300 & 1.600 & 6.600 & 22.953 \\
\hline
\end{tabular}

\footnotetext{
${ }^{90}$ Gay, op. cit., p. 178.

${ }^{91}$ Hemos seleccionado cuarenta y ocho porque para el primer catastro cuarenta y ocho equivalía al $1 \%$ más rico. Por razones de uniformidad mantuvimos este número constante en los otros dos censos.
} 


\begin{tabular}{|c|c|c|c|c|c|c|}
\hline $4-5$ & Correa, Juan de Dios & 14.000 & 12.000 & 1.000 & 12.000 & 18.840 \\
\hline $4-5$ & Ruiz-Tagle, Francisco & 14.000 & 8.000 & 800 & 25.020 & 12.717 \\
\hline 6 & Ballesteros, María & 10.500 & 11.787 & 8.200 & 0 & 48.670 \\
\hline $7-11$ & Calvo Encalda, Martín (Test.) & 10.000 & 11.700 & 3.023 & 14.000 & 43.960 \\
\hline $7-11$ & Fontecilla, Francisco de Borja & 10.000 & 5.000 & 2.000 & 0 & ND \\
\hline $7-11$ & Gutiérrez, Francisco & 10.000 & 3.000 & 0 & 7.500 & 15.700 \\
\hline $7-11$ & Larraín, José Toribio & 10.000 & 7.000 & 800 & 7.000 & 5.495 \\
\hline $7-11$ & Sánchez Dueñas, Francisco Javier & 10.000 & 0 & 0 & 0 & ND \\
\hline 12 & Alcalde, Juan Agustín & 9.000 & 4.500 & 0 & 30.000 & 8.635 \\
\hline 13 & Rosales, José Antonio & 8.050 & 5.000 & 0 & 9.002 & 11.313 \\
\hline $14-15$ & Errázuriz, Isidoro & 7.000 & 5.000 & 700 & 0 & 7.850 \\
\hline $14-15$ & Larraín, Juan Francisco & 7.000 & 3.000 & 100 & 12.000 & 3.140 \\
\hline 16 & Alcalde, Teresa & 6.900 & 364 & 1.350 & 16.100 & 1.256 \\
\hline 17 & Azúa, Ana Josefa & 6.500 & 4.170 & 6.000 & 7.323 & 1.099 \\
\hline 18 & Baeza, Andrés & 6.050 & 3.006 & 1.520 & 12.000 & 2.055 \\
\hline $19-27$ & Bustamante, Manuel José & 6.000 & 5.000 & 900 & 12.000 & 4.396 \\
\hline $19-27$ & Isaguirre, Agustín & 6.000 & 4.000 & 1.000 & 14.000 & 4.710 \\
\hline $19-27$ & Larraín Moxó, Rafael & 6.000 & 5.200 & 0 & 3.000 & ND \\
\hline $19-27$ & Luco, Fernando & 6.000 & 0 & 0 & 0 & ND \\
\hline $19-27$ & Montes, José & 6.000 & 6.000 & 2.000 & 4.000 & 12.560 \\
\hline $19-27$ & Rojas Mercedes & 6.000 & 2.000 & 3.000 & 10.000 & 12.874 \\
\hline $19-27$ & Valdivieso, Francisco Antonio & 6.000 & 2.180 & 200 & 7.000 & 9.891 \\
\hline $19-27$ & Vargas, Carlos & 6.000 & 3.000 & 1.000 & 30.000 & 6.280 \\
\hline $19-27$ & Vicuña, Francisco Ramón & 6.000 & 3.050 & 2.000 & 0 & 56.520 \\
\hline $28-29$ & Rosales, Gertrudis & 5.500 & 4.000 & 500 & 0 & 43.175 \\
\hline $28-29$ & Ruiz Tagle, Manuel & 5.500 & 400 & 800 & 1 & 942 \\
\hline $30-41$ & Argomedo, Gregorio & 5.000 & 4.000 & 300 & 20.000 & 2.198 \\
\hline $30-41$ & Cerda, Francisco & 5.000 & 0 & 0 & 0 & ND \\
\hline $30-41$ & Cerda, José Francisco & 5.000 & 0 & 0 & 0 & ND \\
\hline $30-41$ & Delzo, Juan & 5.000 & 3.000 & 100 & 12.000 & 2.198 \\
\hline $30-41$ & Formas, Ramón & 5.000 & 5.500 & 2.000 & 2.000 & ND \\
\hline $30-41$ & Guzmán, Mercedes & 5.000 & 4.000 & 300 & 35.000 & 7.850 \\
\hline $30-41$ & Huidobro, Vicente & 5.000 & 4.000 & 1.000 & 14.000 & 785 \\
\hline $30-41$ & Molina, Bárbara & 5.000 & 2.000 & 1.000 & 0 & 4.710 \\
\hline $30-41$ & Ortúzar, Manuel & 5.000 & 1.000 & 0 & 0 & 1.727 \\
\hline $30-41$ & Palazuelos, Pedro & 5.000 & 3.600 & 0 & 14.000 & 3.925 \\
\hline $30-41$ & Pérez, Santago & 5.000 & 1.250 & 1.500 & 35.000 & 4.710 \\
\hline $30-41$ & Prado y Sota, Antonio & 5.000 & 4.000 & 0 & 0 & 3.925 \\
\hline 42 & Rozas, José María & 4.700 & 3.040 & 1.000 & 28.000 & 6.318 \\
\hline 43 & García, Tadea & 4.550 & 2.500 & 550 & 18.150 & 1.889 \\
\hline $44-45$ & Pozo, Mercedes & 4.500 & 2.500 & 400 & 0 & 2.669 \\
\hline $44-45$ & Rojas, Agustina & 4.500 & 3.400 & 0 & 10.000 & 8.321 \\
\hline
\end{tabular}




\begin{tabular}{|r|l|r|r|r|r|r|}
\hline 46 & Rozas, Juan Evangelista & 4.300 & 500 & 30 & 16.000 & 628 \\
\hline 47 & Arismendi, Dolores & 4.100 & 0 & 0 & 4.400 & 316 \\
\hline 48 & Izquierdo, Vicente & 4.040 & 2.000 & 1.500 & 20.000 & 6.286 \\
\hline & Subtotal top 48 & 346.310 & 193.277 & 50.473 & 620.096 & 443.520 \\
\hline & TotaL & 1.518 .230 & 559.893 & 580.065 & 15.598 .350 & 2.546 .802 \\
\hline & PARTICIPACIÓN TOP 48 & $23 \%$ & $35 \%$ & $9 \%$ & $4 \%$ & $17 \%$ \\
\hline
\end{tabular}

Fuente: Elaboración propia sobre la base de ANCH-FDGE.

Asimismo, aunque no es el foco de esta sección, nos parece interesante destacar lo siguiente: de la descripción anterior parece quedar claro que los grandes propietarios practicaban tanto actividades ganaderas como vitivinícolas, pero que, a su vez, hubo un importante grado de especialización en ciertas actividades. Lamentablemente, no tenemos información directa del catastro propiamente tal como para determinar con exactitud cuáles de estos grandes propietarios se dedicaban, además, a la producción de trigo, pero seguramente hacían lo propio, dada la ya establecida prevalencia de ese cereal. Por ejemplo, Francisco Javier Sánchez Dueñas figura sin ganado y sin viñas, pero es top 7 de ingresos, lo que presupone que dedicaba sus propiedades principalmente al cultivo de cereales.

Es pertinente destacar una serie de consideraciones sobre el primer censo agrícola y el núcleo superior de terratenientes. Primero, respecto de la distribución de la tierra, no del ingreso como hemos analizado atrás, Francisco Ramón Vicuña, que en el ranking de ingresos (tabla 6) figura en el lugar 26, en posesión de tierra encabeza la lista, siendo propietario de más de 56.000 ha, seguido por María Ballesteros (49.000 ha), quien en el ranking de ingreso anual figura en el sexto lugar. A su vez, los señores Mendiburu ${ }^{92}$ son propietarios de 47.000 ha, seguidos por la testamentaria de Martín Calvo Encalada (44.000 ha, y que en el ranking de ingresos figura en el décimo puesto), mientras que el quinto puesto lo ocupa Gertrudis Rosales, dueña de 43.000 ha. La diferencia que se observa entre los rankings de ingresos y los de posesión de tierra puede tener varias explicaciones, pero la más plausible tiene relación con el hecho innegable que muchas veces grandes porciones de tierra permanecían sin cultivar y, por lo tanto, no generaban ingresos. Esto ocurría por decisión propia de los terratenientes (i.e. percepción de baja rentabilidad) o porque se trataba de tierras marginales de baja fertilidad, como los cerros o los secanos incultivables.

Segundo, el principal propietario de plantas de viñas, de acuerdo con el primer catastro, era Salvador Puga (ciento sesenta mil plantas), seguido por Marcelina Medina (ciento cincuenta mil plantas), Fernando Errázuriz (ciento veintinueve mil plantas), Juan Antonio Urrejola (ciento catorce mil plantas) y José Antonio Alemparte (ciento diez mil plantas). Es notable destacar que de los diez mayores propietarios de plantas de viña, solo uno figura entre los cuarenta y ocho hacendados que generaban más ingresos en Chile en 1832-1834: Fernando Errázuriz. Así, a principios de la década de 1830 el sector vitivinícola no pareciera ser tan gravitante como generador de riqueza en el sec-

\footnotetext{
${ }^{92}$ Se refiere a la familia Mendiburu de Linares, cuya cabeza fue Antonio Urrutia Mendiburu, diputado propietario por Linares durante varios periodos entre 1824 y 1837.
} 
tor agrícola. Este hecho podría atribuirse a diversos factores. Los principales productos generados por los viñedos, vino y aguardientes podrían catalogarse como suntuarios en economías preindustriales caracterizadas por bajos ingresos per capita. Además, los mercados de exportación eran virtualmente inexistentes, producto principalmente de malos sistemas de transporte interno. Así, entonces, la falta de mercados explicaría que el sector vitivinícola no hubiera prosperado durante este periodo.

Tercero, de los grandes hacendados ganaderos, como ya se dijo, Juan de Dios Correa era quien poseía más cabezas de ganado mayor (doce mil), seguido muy de cerca por Martín Calvo Encalada, o su testamentaria, con once mil setecientas cabezas, luego José Nicolás de la Cerda (once mil trecientas cabezas), María Ballesteros (diez mil ochocientas cabezas), José Antonio Valdés (nueve mil ciento sesenta cabezas), Francisco Ruiz Tagle (ocho mil cabezas) y Fernando Errázuriz (siete mil novecientas cabezas). De estos grandes ganaderos, todos figuran en el top-10 de ingresos anuales, lo que sugiere que el subsector ganadero mayor era más relevante que el vitivinícola (y que el del ganado menor), y que, además, tenía gran peso dentro del sector agrario en su conjunto. En otras palabras, buena parte del ingreso total agrícola estaba ligado a la posesión de ganado mayor; este hecho refleja la aún baja participación de la producción agrícola, que comenzará a aumentar en las décadas de 1840 y 1850, cuando se inicien los ciclos exportadores de trigo a California, Australia y, posteriormente, Inglaterra. Ligado a lo anterior, pero respecto de posesión de cabezas de ganado menor, la lista la encabezan María Ballesteros (ocho mil doscientas cabezas), Ana Josefa Azúa (seis mil doscientas cabezas), Juan Nepomuceno de la Cruz (cinco mil trescientas cincuenta cabezas), Martín Arce y José Manuel Irarrázabal (ambos con cuatro mil cabezas cada uno). De estos, solo las señoras Ballesteros y Azúa figuran dentro del 1\% más rico (al menos en cuanto a ingreso anual se refiere), lo que sugiere que el ganado menor no era un gran generador de riqueza para el sector agro-ganadero en su conjunto.

Para el segundo catastro, 1837-1838, el 1\% más rico (entre aquellos que pagaban el impuesto) está integrado por más de noventa propietarios. Para hacerlo comparable con los cuarenta y ocho propietarios listados en la tabla 6, así como más manejable en cuanto a volumen de información, mantendremos la cifra de cuarenta y ocho grandes terratenientes constante. De este modo, la tabla 7 contiene a los cuarenta y ocho propietarios agrícolas más acaudalados de Chile según el catastro de 1837-1838, en cuanto a ingreso anual se refiere, los que poseían un $15 \%$ del total de ingresos anuales de los fundos que pagaban el catastro, además de un $22 \%$ de todo el ganado mayor y un $17 \%$ de la tierra. De estos, dieciocho de ellos (o sus herederos directos) estaban también en el listado de 1832-1834 (i.e. un significativo 38\%). Adicionalmente, de los top 15 de 1832-1834, nueve de ellos aún se mantenían entre los top 27 de 1837-1838, lo que evidencia una clara persistencia de los "súper ricos" en la élite agraria chilena. Además del lapso breve entre el primer y el segundo catastro, este hecho refleja el carácter aún incipiente de la inserción de la economía chilena en la economía internacional, proceso que dará lugar a la formación, en otras actividades, de nuevas fortunas comparables a las del núcleo superior de la élite agraria.

La lista de los mayores ingresos agrícolas en 1837-1838 es encabezada por José Nicolás de la Cerda, con un ingreso anual estimado de \$19.050. Dicho terrateniente ya figuraba en el tercer lugar de mayores ingresos en el ranking de 1832-1834. Comparando 
la información entre ambos censos, podemos observar que aumentó substancialmente la superficie de sus fundos y que entre 1832 y 1838 José N. de la Cerda también invirtió en viñedos, llegando a tener veintiséis mil plantas de viña, mientras que su stock de ganado permaneció relativamente constante. El segundo lugar en el ranking de ingresos anuales lo ocupa María Ballesteros, una perfecta desconocida en la historiografía nacional ${ }^{93}$, pero de quien hablaremos más adelante. La señora Ballesteros percibía un ingreso anual estimado de \$18.500, fruto de dos grandes fundos en la provincia de Santiago. Sabemos con certeza que se dedicaba principalmente a la ganadería, toda vez que contaba con once mil ochocientas y ocho mil seiscientas cabezas de ganado mayor y menor, respectivamente. Muy cerca de María Ballesteros figura Santiago Larraín, con un ingreso anual de $\$ 18.000$, el que se habría originado en la producción triguera principalmente, toda vez que su inversión en viñas y ganado era modesta. Otro agricultor que figuraba en el catastro anterior es José Antonio Valdés, quien ocupa el cuarto lugar en el de 18371838 , con un ingreso anual de $\$ 16.200$, seguido en quinto lugar compartido por Francisco Ruiz Tagle y Juan Agustín Alcalde (ambos con \$14.000 como ingreso anual estimado). En séptimo lugar figura otro agricultor prominente en el anterior catastro, Juan de Dios Correa, mientras que en octavo y noveno lugar se ubican otros dos miembros del clan Larraín: Juan Francisco Larraín (\$13.000) y Rafael Larraín Moxó (\$12.500).

TABLA 7

Ingreso anual agrícola de los cuarenta y ocho hacendados de mayores ingresos del sector agrícola chileno, 1837-1838

\begin{tabular}{|r|l|r|r|r|r|r|}
\hline \multicolumn{1}{|c|}{$\mathbf{N}^{\mathbf{0}}$} & \multicolumn{1}{|c|}{ Propietario } & $\begin{array}{c}\text { Ingreso anual } \\
\text { de fundos }\end{array}$ & $\begin{array}{c}\text { Ganado } \\
\text { mayor }\end{array}$ & $\begin{array}{c}\text { Ganado } \\
\text { menor }\end{array}$ & $\begin{array}{c}\text { Planta } \\
\text { de viña }\end{array}$ & $\begin{array}{c}\text { Hectáreas } \\
\text { de sus fundos }\end{array}$ \\
\hline 1 & De la Cerda, José Nicolás & 19.050 & 10.000 & 1.100 & 26.000 & 65.940 \\
\hline 2 & Ballesteros, María & 18.500 & 11.800 & 8.600 & 0 & 48.670 \\
\hline 3 & Larraín, Santiago & 18.000 & 2.500 & 0 & 9.000 & 1.884 \\
\hline 4 & Valdés, José Antonio & 16.200 & 9.040 & 700 & 24.000 & 14.083 \\
\hline $5-6$ & Alcalde, Juan Agustín & 14.000 & 8.500 & 400 & 57.000 & 9.913 \\
\hline $5-6$ & Ruiz Tagle, Francisco & 14.000 & 8.000 & 800 & 45.000 & 12.717 \\
\hline 7 & Correa, Juan de Dios & 13.700 & 20.000 & 7.000 & 13.000 & 19.083 \\
\hline 8 & Larraín, Juan Francisco & 12.500 & 4.100 & 600 & 40.000 & 7.379 \\
\hline 9 & Larraín Moxó, Rafael & 12.000 & 9.000 & 500 & 8.000 & 10.990 \\
\hline 10 & Valdivieso, Valentín & 11.000 & 3.000 & 2.000 & 9.000 & 31.400 \\
\hline 11 & Irarrázabal, José Miguel & 10.000 & 4.900 & 950 & 49.000 & 9.420 \\
\hline $12-13$ & Errázuriz, Fernando & 10.000 & 0 & 0 & 7.500 & 15.700 \\
\hline $12-13$ & Gutiérrez, Francisco & 9.500 & 12.030 & 800 & 90.200 & 9.970 \\
\hline 14 & Alemparte, José Antonio & & & & \\
\hline
\end{tabular}

\footnotetext{
${ }^{93} \mathrm{Su}$ nombre no figura en ningún artículo indexado, y tampoco hay entradas para ella en los principales diccionarios biográficos chilenos, por ejemplo.
} 


\begin{tabular}{|c|c|c|c|c|c|c|}
\hline 15 & Portales, Estanislao & 9.100 & 3.750 & 1.000 & 26.300 & 2.136 \\
\hline 16 & Sánchez Dueñas, Francisco Javier & 9.000 & 3.500 & 0 & 18.500 & ND \\
\hline 17 & Vergara y Sepúlveda, Francisco & 8.700 & 4.400 & 6.100 & 11.000 & 30.615 \\
\hline 18 & Ovalle y Vivar, Ramón & 8.300 & 500 & 800 & 80.000 & 440 \\
\hline $19-20$ & Azúa, Ana Josefa & 8.000 & 4.170 & 5.000 & 7.325 & 34.540 \\
\hline $19-20$ & Errázuriz, Javier & 8.000 & 6.040 & 200 & 28.000 & 3.611 \\
\hline 21 & Mendiburues, señores & 8.000 & 3.000 & 3.000 & 40.000 & 64.370 \\
\hline 22 & Munizaga, Juan Miguel & 7.950 & 1.000 & 2.300 & 0 & 628 \\
\hline 23 & Tagle, Manuel & 7.500 & 1.600 & 300 & 5.500 & 3.485 \\
\hline $24-27$ & Bustamante, Manuel & 7.000 & 5.004 & 940 & 13.500 & 4.431 \\
\hline $24-27$ & Hermida, Antonio & 7.000 & 0 & 800 & 50.000 & 1.099 \\
\hline $24-27$ & Rosales, José Antonio & 7.000 & 3.300 & 3.000 & 8.000 & 7.222 \\
\hline $24-27$ & Vicuña, Francisco Ramón & 7.000 & 3.500 & 2.000 & 0 & 56.520 \\
\hline 28 & Larraín, Agustín & 6.800 & 4.040 & 800 & 2.000 & 12.796 \\
\hline 29 & Errázuriz, Isidoro (herederos) & 6.700 & 5.000 & 850 & 2.700 & 7.850 \\
\hline 30 & Salas, Pedro & 6.500 & 2.560 & 1.500 & 25.000 & 4.082 \\
\hline 31 & Baeza, Andrés & 6.400 & 3.000 & 500 & 4.000 & 2.066 \\
\hline 32 & Echaurren, Juan Manuel & 6.100 & 1.100 & 300 & 22.000 & 1.853 \\
\hline 33 & Izquierdo, Vicente & 6.000 & 2.000 & 1.500 & 20.000 & 6.286 \\
\hline 34 & Eyzaguirre, Agustín & 6.050 & 4.000 & 1.000 & 14.000 & 4.712 \\
\hline 35 & Aránguiz, Antonio & 6.000 & 400 & 1.000 & 8.000 & ND \\
\hline $36-45$ & De Ovalle & 6.000 & 1.000 & 466 & 800 & 3.140 \\
\hline $36-45$ & Los Vargas & 6.000 & 100 & 300 & 0 & ND \\
\hline $36-45$ & Luco, Fernando & 6.000 & 0 & 0 & 0 & ND \\
\hline $36-45$ & Luco, Pedro Nolasco (finado) & 6.000 & 300 & 500 & 40.000 & 273 \\
\hline $36-45$ & Prado y Sota, Antonio & 6.000 & 4.000 & 0 & 0 & 3.925 \\
\hline $36-45$ & Rojas, Mercedes & 6.000 & 2.000 & 3.000 & 10.000 & 12.874 \\
\hline $36-45$ & Ruiz Tagle, Manuel & 6.000 & 350 & 1.000 & 4.000 & 942 \\
\hline $36-45$ & Velasco y Castillo, Señoras & 6.000 & 0 & 400 & 50.000 & 184 \\
\hline $36-45$ & Valladares, Elena & 6.000 & 4.000 & 400 & 20.000 & 2.355 \\
\hline $36-45$ & Vargas, Carlos & 6.000 & 3.000 & 1.000 & 30.000 & 6.280 \\
\hline 46 & Elizondo, Diego Antonio & 5.900 & 1.000 & 1.500 & 10.000 & 2.983 \\
\hline $47-48$ & Cerda, José Francisco & 5.500 & 0 & 0 & 0 & ND \\
\hline \multirow[t]{4}{*}{$47-48$} & Ossa, Francisco Ignacio & 5.500 & 2.000 & 25 & 1.519 & 3.677 \\
\hline & Subtotal top 48 & 421.450 & 188.484 & 65.931 & 929.844 & 548.488 \\
\hline & TOTAL & 2.760 .630 & 781.553 & 942.999 & 25.010 .120 & 3.234 .260 \\
\hline & PARTICIPACIÓN TOP 48 & $15 \%$ & $24 \%$ & $7 \%$ & $4 \%$ & $17 \%$ \\
\hline
\end{tabular}

Fuente: Elaboración propia sobre la base de ANCH-FDGE. 
Al igual que como hicimos para 1832-1834, la información de 1837-1838 nos permite rankear también a los propietarios de fundos agrícolas de acuerdo con el número de hectáreas que poseían. En 1837-1838 el mayor propietario de tierra en Chile sería José Nicolás de la Cerda (ocupaba el octavo lugar en el catastro de 1832-1834), dueño de casi 66.000 ha, seguido por los señores Mendiburu (64.000 ha), Francisco Ramón Vicuña (56.000 ha), María Ballesteros (49.000 ha) y Gertrudis Rosales (43.000 ha). En suma, hubo pocos cambios en la posesión de la tierra de los grandes latifundistas de Chile, lo que no es de extrañar considerando el poco tiempo transcurrido entre los dos primeros censos agrícolas.

Respecto de la inversión en plantas de viña, los principales actores en 1837-1838 eran todos del departamento de Puchacai, en la provincia de Concepción: Manuel Zañartu, con doscientos veintidós mil plantas, duplicando su stock de plantas respecto del catastro previo, cuando ocupaba el sexto lugar en el ranking de los dueños de plantas de viña; Pedro Zañartu (ciento noventa y un mil plantas); Tomasa Santa María (ciento ochenta y cuatro mil plantas) y José María Palominos (ciento ochenta mil plantas). Entre los ganaderos (ganado mayor) más potentados para este segundo catastro, destacan en particular Juan de Dios Correa (veinte mil cabezas), quien también rankeaba primero en el catastro anterior; José Antonio Alemparte (doce mil cabezas); María Ballesteros (once mil ochocientas cabezas); José Nicolás de la Cerda (diez mil cabezas); José Antonio Valdés (nueve mil cabezas). Respecto del ganado menor, la lista la encabezan Javier Manzano (doce mil cabezas de ganado menor); Francisco González (nueve mil cabezas); María Ballesteros, quien en el catastro pasado era top 1 (ocho mil seiscientas cabezas); Manuel Prieto (ocho mil quinientas cabezas) y Juan de Dios Correa (siete mil cabezas).

A continuación, para caracterizar a los grandes terratenientes en Chile en la década de 1830, analizaremos el perfil de los más importantes (los top 10 en cada catastro, ordenados por ingreso, agregando, además, al mayor propietario de tierra de Chile en ese entonces). De este modo, el núcleo de la élite agraria quedaría conformado por: Fernando Errázuriz, José Antonio Valdés, José Nicolás de la Cerda, Juan de Dios Correa, Francisco Ruiz Tagle, Francisco Borjas Fontecilla, Francisco Javier Sánchez Dueñas, José Toribio Larraín, Santiago Larraín Moxó, Juan Francisco Larraín, Rafael Larraín Moxó, Martín Calvo Encalada, María Ballesteros, Juan Agustín Alcalde, Valentín Valdivieso, José Miguel Irarrázabal y Francisco Ramón Vicuña ${ }^{94}$.

El primero de esos grandes propietarios, Fernando Errázuriz (1777-1841), era abogado y antes de la Independencia ocupó el cargo de alcalde por el Cabildo de Santiago.

${ }^{94}$ Toda la información biográfica de estos personajes fue extraída de las siguientes fuentes: Amunátegui del Solar, Mayorazgos y títulos..., op. cit., tomos I y II; Diego Barros Arana, Historia jeneral de Chile, Santiago, Rafael Jover Editor, 1884-1904; Narciso Desmadril y Hergómenes de Irisarri (eds.), Galería nacional o Colección de biografias y retratos de hombres célebres de Chile, Santiago, Imprenta Chilena,1854; Pedro Pablo Figueroa, Diccionario biográfico de Chile, Santiago, Encuadernación e Imprenta Barcelona, 1897; Virgilio Figueroa, Diccionario histórico y biográfico de Chile, Santiago, Imprenta y Litografía La Ilustración, Santiago, 1925; Julio Retamal Favereau, Carlos Celis Atria, José Miguel de la Cerda Merino, Carlos Ruiz Rodríguez y Francisco José Urzúa Prieto, Familias fundadoras de Chile 1656-1700. El conjunto final, Santiago, Ediciones Universidad Católica de Chile, 2003; Luis Thayer Ojeda, Orígenes de Chile: elementos étnicos, apellidos, familias, Santiago, Andrés Bello, 1989. 
Con posterioridad, fue diputado y senador, llegando a ocupar la presidencia del Senado y la vicepresidencia de la República. Todos sus fundos se ubicaban en la provincia de Santiago. Se casó con Carmen Sotomayor, y su hijo mayor, José Javier, figura en el lugar veintitrés de los mayores ingresos agrícolas de Chile en 1852. Vemos acá cómo el hacendado más acaudalado de Chile en 1832 tenía fuertes nexos con la clase política, siendo parte integral de la misma, antes y después de la Independencia. El segundo en la lista es José Antonio Valdés, descendiente del marqués de Casa Real (a través de su madre, Margarita García-Huidobro Morandé), uno de los siete hombres más ricos al final de la Colonia listados por Ricardo Couyoumdjian. Al igual que el caso anterior, fue poseedor de fundos en la provincia de Santiago y ocupó cargos públicos antes de la Independencia, siendo, incluso, alcalde de Santiago entre 1800 y 1801. Posteriormente, como el ya mencionado Fernando Errázuriz, fue diputado por Rancagua durante la República.

El tercer personaje en nuestra lista, y de hecho también tercero en el ranking de grandes ingresos de 1832-1834, es José Nicolás de la Cerda, heredero del mayorazgo de la Cerda. Es este otro caso notable de una fortuna proveniente de la época colonial y que posteriormente ocupó asientos en el parlamento chileno, siendo diputado por Santiago, aun cuando todos sus fundos se encontraban en La Ligua, provincia de Aconcagua. Cuarto en nuestro listado es Juan de Dios Correa, de los pocos grandes hacendados que permaneció vivo en todo nuestro periodo de estudio y que figura, además, entre los top 48 en nuestros tres listados. Todos sus fundos se encontraban en la provincia de Santiago. Aun cuando fue militar, patriota, diputado y senador, por su matrimonio con Nicolasa de Toro y Zambrano, hija del conde de la Conquista, tenía fuertes nexos familiares con, nuevamente, uno de los siete hombres más ricos al final de la Colonia. El quinto personaje seleccionado es Francisco Ruiz Tagle, diputado, senador (presidente del Senado en 1813), ministro de Hacienda, que, incluso, llegó a ser Presidente de la República interino durante algunas semanas en 1830; era, indudablemente, otro terrateniente perteneciente a la alta élite política chilena. Seguimos nuestro análisis con Francisco de Borja Fontecilla (militar de formación), otro personaje ligado a la élite colonial, toda vez que su padre fue corregidor de La Serena antes de la Independencia. Como todos los casos anteriores, también fue parlamentario, llegando a ocupar la presidencia del Senado. Resumiendo, de estos primeros seis casos analizados, podemos constatar que todos fueron parlamentarios, y que la mayoría de ellos ocuparon, además, altísimos cargos de gobierno.

El siguiente caso es el de Francisco Javier Sánchez Dueñas, quien llama la atención por no haber tenido cargos en el parlamento ni en el gobierno y cuya profesión registrada en diccionarios biográficos es "agricultor". Seguimos, entonces, con José Toribio Larraín Moxó, hermano cuatro años menor de Rafael Larraín Moxó (véase más adelante), quien, al igual que su hermano, estuvo fuertemente ligado a la élite colonial a través del marquesado Larraín y el mayorazgo Larraín Vicuña, pero que tuvo un bajo perfil político (i.e. no ocupó asientos parlamentarios ni puestos de gobierno). El décimo en la lista es otro miembro del clan Larraín Moxó, Santiago (hermano de Rafael y José Toribio, menor que Rafael, pero mayor que José Toribio), quien no tuvo carrera parlamentaria ni cargos públicos. Le sigue Juan Francisco Larraín, abogado y militar, del linaje del ma- 
yorazgo Rojas, lo que también lo liga, como otros tantos, a la élite colonial. Fue diputado en varias ocasiones, por Rancagua y San Carlos. Completa el listado de los Larraín, Rafael Larraín Moxó, uno de los agricultores más importantes del periodo y del que, por ello, trataremos en detalle más adelante.

El siguiente en el listado es Martín Calvo Encalada, coronel, diputado y senador en la República, quién murió antes de realizarse el primer catastro, pero a quien hemos incluido, pues los fundos seguían a nombre de la testamentaria, en pleno litigio al momento de realizarse dicho catastro. También ha sido considerado porque su padre, Manuel Calvo Encalada, no es otro sino el marqués de Villa Palma, otro de los siete grandes potentados de la capital a fines del periodo colonial, reafirmando una vez más los fuertes nexos entre la élite nacional de fines de la Colonia y comienzos de la República. Le sigue María Ballesteros, cuyo nombre completo era María Rodríguez de Ballesteros y Taforó ${ }^{95}$, viuda de José María Fernández Balmaceda, fue la abuela de José Manuel Balmaceda, futuro presidente de Chile y, desde luego, estaba directamente ligada también a la élite colonial, pero limeña, toda vez que fue hija del regente de la Audiencia de Lima. La señora Ballesteros administró hasta su muerte el extenso fundo de Bucalemu.

Otro personaje interesante de analizar es Juan José Agustín Alcalde, hijo de José Antonio Alcalde, "tercer conde de Quinta Alegre", quien nuevamente se encontraba entre los siete hombres más ricos de Chile en c. 1790. Fue diputado por varios distritos, senador y presidente del Senado, heredando, incluso, el título de "cuarto conde de Quinta Alegre". El antepenúltimo de nuestros personajes es Valentín Valdivieso, abogado y diputado, y quien llegó a ser arzobispo de Santiago (luego de ordenarse sacerdote en 1834). El penúltimo hacendado a analizar es José Miguel Irarrázabal. Abogado y regidor por Santiago (1825), diputado y senador, y como tantos otros en este listado, presidente del Senado. Ligado también a las viejas élites coloniales, siendo, en efecto, el sexto marqués de Pica. Termina la lista Francisco Ramón Vicuña, otro gran hacendado con grandes conexiones políticas y rango militar (coronel), ocupando escaños en el parlamento, siendo presidente del Senado y vicepresidente provisional de la República, estando, además, conectado a las élites coloniales gracias a su matrimonio con Mariana Aguirre, hija de los marqueses de Montepío.

Además de los claros y sistemáticos nexos que hemos presentado entre la élite terrateniente de la República temprana con la élite colonial, una pregunta relevante que emerge del análisis anterior es la siguiente: ¿Cómo se comparan estos grandes terratenientes con los de la región? Solo podemos hacer comparaciones con la élite bonaerense de 1839. De acuerdo con datos de Jorge Gelman y Daniel Santilli ${ }^{96}$, podemos comparar el stock ganadero (mayor y menor combinado), y la conclusión más clara es que la élite de Buenos Aires era mucho más rica que la chilena en este rubro. Por ejemplo, los Anchorena eran propietarios de más de ciento treinta y seis mil cabezas de ganado, Juan

\footnotetext{
${ }^{95}$ Raúl Silva Castro, Cartas de Juan Egaña 1832-1833, Santiago, Imprenta Universitaria, 1951, pp. 15.

${ }^{96}$ Gelman y Santilli, De Rivadavia a Rosas..., op. cit., pp. 157-158. En otros países de la región, para nuestro periodo de estudio, el sector agrícola no estaba muy desarrollado como, por ejemplo, en el caso peruano y uruguayo y, por tanto, las élites terratenientes eran (relativamente) poco prominentes. Piel, op. cit.; Moraes y Pollero, op. cit.
} 
Manuel Rosas poseía casi cincuenta mil, Ildefonso Ramos Mejía más de treinta mil cabezas, mientras que Juan Terrero casi treinta mil. Vale decir, los Anchorenas tenían unas siete veces más cabezas de ganado que el chileno que más cabezas tenía en 1832 y 1838, quien no alcanzaba las quince mil cabezas y veintiún mil cabezas en 1832 y 1838 , respectivamente. Respecto de la posesión de plantas de viñas o hectáreas cultivadas con cereales, lamentablemente no podemos realizar comparaciones, pero sabemos que la élite terrateniente de Buenos Aires se especializaba en ganado, por lo que es razonable suponer que en estos otros rubros (e.g. trigo y viñedos) estaban por debajo de los grandes latifundistas chilenos de la época.

\section{TABLA 8}

Ingreso anual agricola de los cuarenta y ocho hacendados con mayores ingresos del sector agrícola chileno,

\section{2}

\begin{tabular}{|c|c|c|c|c|c|}
\hline $\mathbf{N}^{\mathbf{o}}$ & Propietario & $\begin{array}{c}\text { Ingreso } \\
\text { anual } \\
\text { estimado }\end{array}$ & $\mathbf{N}^{\mathbf{o}}$ & Propiretario & $\begin{array}{c}\text { Ingreso } \\
\text { anual } \\
\text { estimado }\end{array}$ \\
\hline 1 & Correa, Juan de Dios & 103.050 & 25 & Solar, Bernardo & 16.000 \\
\hline 2 & Cortez Azua, Felipe & 60.000 & 26 & Izquierdo, José Vicente (Test.) & 15.800 \\
\hline 3 & Subercaseaux, Ramón & 59.512 & 27 & Iñiguez, Pedro Felipe & 15.354 \\
\hline 4 & Ruiz Tagle, Francisco & 52.500 & $28-29$ & Concha, Santiago M. & 15.000 \\
\hline 5 & De la Cerda, José Nicolás (heredero) & 44.728 & $28-29$ & Ortúzar, José Ángel & 15.000 \\
\hline 6 & Ossa, Francisco Ignacio & 41.450 & 30 & Prado, Miguel & 14.700 \\
\hline 7 & Sánchez Dueñas, Francisco Javier & 33,448 & 31 & Matte, Domingo & 14.100 \\
\hline 8 & Ovalle, Francisco Javier & 29.500 & 32 & Hurtado, José María & 14.000 \\
\hline 9 & Larraín Moxó, Rafael & 27.700 & 33 & Ganderillas, Joaquín & 13.828 \\
\hline 10 & Valdivieso, Valentín & 27.300 & 34 & Sánchez, Ambrosio & 13.500 \\
\hline 11 & Fernández, Manuel y Braulio & 26.700 & 35 & Álvarez, Pablo & 13.470 \\
\hline 12 & Correa, Rafael (Test.) & 25.000 & 36 & Ovalle, Diego & 13.200 \\
\hline 13 & Alcalde, Juan Agustín & 24.800 & 37 & Hurtado, Manuel José & 13.105 \\
\hline 14 & Arriagada, Francisco & 23.385 & $38-39$ & Caldera, Máximo & 13.000 \\
\hline 15 & Gatica, José Manuel & 21.950 & $38-39$ & Waddington, Joshua & 13.000 \\
\hline 16 & Cousiño, Matías & 21.448 & 40 & Antunez, Nemecio & 12.600 \\
\hline 17 & Larraín, Patricio & 21.000 & 41 & Irarrázaval, Manuel & 12.500 \\
\hline 18 & Ossa Varas, Blas & 19.300 & 42 & Eyzaguirre, Manuel & 12.375 \\
\hline 19 & Sánchez, José Vicente & 18.494 & $43-47$ & Gandarillas, Juan de la Cruz & 12.000 \\
\hline 20 & Ortúzar, Ignacio & 18.390 & $43-47$ & Luco, Pedro José & 12.000 \\
\hline 21 & Borja Larraín, Francisco & 18.135 & $43-47$ & Ramírez, Dolores & 12.000 \\
\hline 22 & Rojas, Mercedes & 18.000 & $43-47$ & Undurraga, Ramón & 12.000 \\
\hline 23 & Errázuriz, Francisco Javier & 17.900 & $43-47$ & Vegas, Nicolás & 12.000 \\
\hline 24 & Videla, Francisco & 17.500 & 48 & Vicuña, Joaquín & 11.900 \\
\hline
\end{tabular}

Fuente: Elaboración propia sobre la base de Chile 1855. 
Siguiendo con nuestro análisis de las élites del campo chileno, el tercer catastro se realizó en 1852, veinte años después de iniciado el primero. Para este catastro no tenemos información sobre extensión de los fundos (hectáreas), plantas de viña y ganado; es relevante que dicha información no haya sido registrada, considerando que ya en 1852 la vitivinicultura se había transformado en una actividad destacada del agro chileno ${ }^{97}$. No obstante, es posible rankear a los terratenientes de acuerdo con el ingreso estimado de sus fundos. La tabla 8 contiene a los cuarenta y ocho hacendados más pudientes en 1852, quienes en conjunto generaban un $15 \%$ del ingreso total de los más de treinta $\mathrm{y}$ tres mil fundos que pagaban el catastro, una proporción significativa. Juan de Dios Correa, que ocupaba el cuarto lugar en el catastro de 1832, ahora encabeza el listado, con un ingreso anual de $\$ 103.050$, muy distante del segundo y tercero, Felipe Cortez Azúa (\$60.000) y Ramón Subercaseaux ${ }^{98}$ (también \$60.000). En el cuarto lugar figura Francisco Ruiz Tagle (\$52.500), seguido por el mayorazgo de la Cerda (\$45.000), antes liderado por José Nicolás de la Cerda (muerto en 1847, antes de realizarse este tercer catastro), quien figuraba en el tercer y primer lugar en 1832-1834 y 1837-1838, respectivamente. Su hijo, de nombre homónimo, lideraba la familia en ese entonces. En sexto lugar aparece Francisco Ignacio Ossa, quien ya en 1837-1838 figuraba entre los top 48 de Chile. Muchos otros nombres entre los top 48 de la década de 1830 (o sus herederos directos) se repiten en 1852, a saber: Juan Agustín Alcalde, Rafael Larraín Moxó, Mercedes Rojas y Valentín Valdivieso. Adicionalmente, es clara también la persistencia de ciertas familias en el periodo que trata este artículo, destacando los siguientes: Alcalde, Correa, de la Cerda, Sánchez Dueñas, Errázuriz, Eyzaguirre, Irarrázabal, Izquierdo, Larraín, Luco, Ossa, Ovalle, Prado, Rojas, Ruiz Tagle, Valdivieso y Vicuña. En suma, es posible comprobar la clara persistencia de la élite agraria de principios de la República hasta mediados del siglo XIX, tanto en términos de individuos como de familias. No obstante, es interesante destacar que en 1852, por primera vez, un extranjero integra el grupo superior de los cuarenta y ocho propietarios de mayores ingresos: Joshua Waddington, en el lugar treinta y nueve de la lista de grandes hacendados. Este es un hito en la historia agraria chilena, toda vez que hasta entonces los hombres de negocios extranjeros normalmente se concentraban en el comercio exterior o en el sector minero del país. Por ello, la figura de Joshua Waddington se examina más adelante, en relación con el ingreso de nuevos empresarios al sector agropecuario.

Si para los catastros de 1832-1834 y 1837-1838 seleccionamos los diez mayores ingresos para considerar su perfil biográfico, en este último apartado haremos lo propio, pero excluyendo a los que ya hemos caracterizado. El primero de ellos es Ramón Subercaseaux, de origen francés, miembro del Partido Conservador, al cual representó ocupando asiento en el Senado por casi veinte años. Fue propietario de grandes haciendas como Pirque, El Llano y Colmo. Le sigue Francisco Ignacio Ossa, sin nexos con la élite

${ }^{97}$ Ricardo Nazer Ahumada, "El surgimiento de una nueva elite empresarial en Chile: 1830-1880", en Franco Boneli e María Rosario Stabili. (eds.), Minoranze e culture imprenditoriali. Cile e Italia (secoli XIX$X X)$, Roma, Università di Roma, 2002, pp. 75.

${ }^{98}$ Ramón Subercaseaux no figuraba entre los propietarios principales en 1832, sí lo hacía en 1837-1838, rankeando en el lugar sesenta y seis en todo Chile. 
colonial, pero quien ocupó cargos de gobierno en la Municipalidad de Copiapó después de la Independencia, antes de mudarse a Santiago, siendo luego electo primero diputado luego senador por más de veinte años, en principio gracias a sus fuertes nexos con Diego Portales. Buena parte de su fortuna proviene de actividades mineras, sobre todo de la explotación de Chañarcillo, siendo uno de los primeros propietarios de la mina descubridora de dicho yacimiento. Conocido para los santiaguinos como el palacio de la Alhambra (monumento nacional), ubicado en la calle Compañía ${ }^{99}$. Por su parte, Francisco Javier Ovalle, abogado, otro gran hacendado con una nutrida carrera parlamentaria, siendo tanto diputado como senador, y que ocupó, además, altos cargos de gobierno, destacando como ministro de Justicia, Culto e Instrucción Pública a mediados del decenio de 1850. Finalmente, Manuel Fernández, quien por ser uno de los pocos grandes hacendados de nuestra muestra que haya nacido en España, no incursionó en carrera parlamentaria, dedicándose plenamente a los negocios. Junto a su primo Braulio, fue uno de los herederos de la ya mencionada hacienda de Bucalemu, originalmente propiedad de su tío, José María Fernández Balmaceda, la cual al morir María Ballesteros pasó a ser administrada por ellos, lo que explica el origen de sus fortunas.

Antes de terminar nuestro examen general de las grandes fortunas de 1852, cabe resaltar otro hecho significativo que ya hemos insinuado anteriormente. Al combinar la información de los catastros con la de otras fuentes (que contienen listados de miembros del parlamento $)^{100}$, es posible demostrar que la participación de los terratenientes de mayores ingresos en la élite política chilena fue extraordinariamente significativa. En efecto, de los cuarenta y ocho grandes hacendados de 1852, veintinueve fueron diputados, senadores, o ambos, cifra que representa un alto porcentaje de la muestra (60\%). Así, no solo formaban parte de la élite terrateniente sino, también, de la reducida élite política nacional de la década de 1850 y, desde luego, también de la de las décadas anteriores, pues se constata la misma relación en los rankings de agricultores de mayores ingresos en los primeros dos catastros. Para el catastro de 1832-1834, de los quince hacendados más acaudalados, once $(73 \%)$ fueron miembros del parlamento chileno (y veinticuatro de los cuarenta y ocho, un 50\%). Por su parte, para el ranking de 1837-1838, veinte de los cuarenta y ocho (42\%) potentados del agro fueron diputados o senadores (y muchas veces ambos). En conclusión, todos estos guarismos son contundentes para probar el nexo anunciado.

Por otra parte, la información proporcionada por los sucesivos catastros considerados en este trabajo permite discutir importantes procesos en la élite agraria de la primera mitad del siglo xIx, así como revisitar ciertos elementos del debate historiográfico y de la interpretación convencional sobre el sector agropecuario, los que podemos tratar enfocándonos en la trayectoria de dos figuras relevantes: Rafael Larraín Moxó y Joshua Waddington. Perteneciente al poderoso clan Larraín e hijo mayor de José Toribio La-

${ }^{99}$ Daniel Palma, Plata, poder y beneficencia. La vida de Francisco Ignacio Ossa Mercado, 1793-1864, tesis de Magister, Santiago, Universidad de Santiago de Chile, 2002.

${ }^{100}$ Germán Urzúa Valenzuela, Historia politica de Chile y su evolución electoral: desde 1810 a 1992, Santiago, Editorial Jurídica de Chile, 1992; Manuel Montt, Cuadro histórico de la administración Montt, escrito según sus propios documentos. Valparaíso, Imprenta y Librería del Mercurio, 1861; Agustín Edwards, Cuatro presidentes de Chile 1841-1876, Valparaíso, Sociedad Imprenta y Litografía Universo, 1932, tomos I y II. 
rraín y Guzmán, el marqués de Larraín desde 1787, Rafael Larraín Moxó (1813-1892) es un ejemplo notable de los grandes terratenientes de raíz colonial que se constituyeron en "agricultores progresistas" y que tempranamente buscaron impulsar la modernización de la agricultura. Así, su trayectoria empresarial demuestra que la caracterización de los grandes terratenientes como un sector homogéneo de latifundistas retrógrados es una simplificación de la complejidad de esa clase social, en la que, en realidad, existían distintos sectores y grupos. Como sugiere el ingreso anual de sus propiedades registradas en los catastros, el que se cuadruplicó entre 1832-1834 y 1852 (tablas 6, 7 y 8), se trata de una fortuna ascendente en el conjunto de la élite agraria. Al mismo tiempo, ese ascenso reflejó una importante transformación en el sector agropecuario, como fue la expansión de la agricultura del sistema de hacienda, producto del impacto de la demanda de cereales en los mercados internacionales. Así, en 1861, es decir, nueve años después del catastro de 1852, Rafael Larraín Moxó empezó a aumentar la superficie cultivada con trigo en la hacienda Viluco, ubicada en el valle del Maipo, duplicándola en solo diez años, de 706 ha en 1861 a 1.621 ha en 1871, demostrando su capacidad para responder a los estímulos del mercado.

Más aún, tras vender la hacienda Cauquenes en 1867, Rafael Larraín Moxó concentró su actividad en Viluco. Sus inversiones dieron lugar a un proceso de modernización que la convirtieron en una hacienda altamente mecanizada, especializada y eficiente, es decir, un "fundo modelo", según la expresión de la época. Como tal, en 1872 fue objetivo de un reportaje de Julio Menadier, redactor jefe del Boletín de la Sociedad Nacional de Agricultura, quien consignó que Viluco tenía un completo equipo agrícola. Este incluía "180 arados Howard \& Grignon, dos motores a vapor, dos motores de agua [ruedas hidráulicas], una trilladora Ransomes, tres trilladoras Pitt, dos aventadoras, diez cribas rotatorias, un molino mecánico portátil y movido a vapor, una tascadora movida a vapor, una desgranadora a vapor, una aserradora a vapor Buckley, cinco segadoras Governor; además de trituradoras, destroncadoras, gradas, rodillos, etc.". Asimismo, destacó el empleo de máquinas a vapor como fuente principal de energía y la organización del proceso de producción. Así, señaló: "los grandes almacenes de máquinas y herramientas no sólo llaman la atención [...] por su orden, simetría y buen arreglo, sino también por la injeniosa colocación de los locomóviles, que pueden hacer funcionar toda la maquinaria empleada para la esplotacion de las industrias agrícolas, y ademas un molino mecánico, aserradoras, prensas y otros aparatos con solo ponerles las correas"101.

Rafael Larraín Moxó también participó activamente en las instituciones creadas por el sector de "hacendados progresistas" al que pertenecía y que, como él, estaba compuesto mayoritariamente por agricultores de distinguidas familias de la élite agraria. Así, fue socio fundador de la Sociedad Nacional de Agricultura, creada en 1869 como proyección orgánica de la Exposición Nacional de Agricultura, realizada en mayo de ese año, y fundada con el propósito central de fomentar la "agricultura científica" en el país. En esa perspectiva, destaca, además, el informe que Rafael Larraín Moxó realizó en 1873 sobre la deforestación en Chile Central, el que sirvió de base para la primera legislación que

${ }^{101}$ Julio Menadier, "La Hacienda Viluco", en Boletín de la Sociedad Nacional de Agricultura, vol. III, № 11, Santiago, 1872. 
limitó la explotación de los bosques ${ }^{102}$. Anteriormente, en 1844, y por encargo de la SA, elaboró la primera propuesta sobre "legislación de aguas" del campo chileno ${ }^{103}$. Además, siendo vicepresidente de la SNA, presidió el Primer Congreso Libre de Agricultores, una asamblea programática de la élite modernizadora, celebrada en Santiago durante un mes completo en 1875. En ella participaron las autoridades de gobierno, los "hacendados progresistas" y conspicuos miembros de la oligarquía agraria y empresarial. Aunque contó con la participación de ciento treinta y nueve delegados desde Atacama a Chiloé, en su mayoría fueron grandes agricultores de provincias de Chile Central, en las que se había desarrollado la expansión agraria impulsada por el aumento de las exportaciones de trigo. El programa modernizador de la asamblea presidida por Rafael Larraín Moxó incluía el estudio del avalúo de los predios agrícolas, la elaboración de un código rural, la creación del Ministerio de Agricultura, la fundación de un instituto agrícola y escuelas de agricultura, el establecimiento de un laboratorio de Química Industrial para la agricultura y la creación de sociedades de construcciones rurales y de importación de maquinaria agrícola ${ }^{104}$.

Al igual que muchos grandes agricultores, Rafael Larraín Moxó era en realidad un empresario con una variedad de inversiones en distintas actividades. Comenzando a mediados de la década de 1850 con la compra de acciones en el Ferrocarril del Sur, participó en al menos dieciséis sociedades anónimas y presidió varias de ellas. Su carrera siguió con el Banco de Chile (que también presidió), la Compañía Explotadora de Lota y Coronel y el Banco Sudamericano, entre muchas otras, mostrando un impresionante grado de diversificación en su cartera. Su actividad empresarial registra también una serie de iniciativas importantes. Así, en 1855 fue accionista de la compañía de seguros mutuos El Porvenir de las Familias, en la que también participaba José Tomás Urmeneta; y en 1869 era presidente de la Compañía Chilena de Depósitos y Consignaciones, que tenía un capital suscrito de $\$ 2.000 .000$, y giraba en la "compra y venta de toda clase de frutos del país, por consignación o mediante depósito en sus bodegas, importación de mercaderías, etc." ${ }^{105}$. Más tarde, en 1872 fue accionista de la Compañía Agrícola, la primera sociedad anónima en el sector y de la que también formó parte José Manuel Balmaceda. Finalmente, tuvo una larga carrera política. Desde mediados de la década de 1850 hasta comienzos de la de 1880, fue diputado, senador y presidente del Senado; además, era socio fundador del Club de la Unión y miembro de la Comisión de los Constituyentes $^{106}$. En suma, habiendo aumentado su fortuna agrícola desde la década de 1830, como indican los catastros, constituye un caso de agricultor modernizador y activo inversionista con anterioridad al ingreso de comerciantes y mineros que, según observó Claudio Gay en 1862, invirtieron parte de sus fortunas en el sector agropecuario hacia $1850^{107}$.

${ }^{102}$ Rafael Larraín Moxó, Corta de bosques: Informe de la comisión nombrada para dictaminar esta materia i reglamento dictado por el Presidente de la República, Santiago de Chile, Imprenta Nacional, 1873.

${ }^{103}$ El Agricultor, № 47, Santiago, julio 1844 y No 48, agosto 1844.

${ }^{104}$ Robles, Hacendados progresistas..., op. cit., pp. 28-33.

${ }^{105}$ El Araucano, Santiago, 28 de noviembre de 1868.

${ }^{106}$ Club de la Unión, Reglamento del Club de la Unión, Valparaíso, Imprenta del Mercurio, 1859; Justo Arteaga Alemparte y Domingo Arteaga Alemparte, Los Constituyentes de 1870, Santiago, Imprenta Barcelona, 1910.

${ }^{107}$ Claudio Gay, Agricultura chilena, Santiago, ICIRA, 1973, tomo I, p. 106. 
Si la trayectoria de Rafael Larraín Moxó demuestra que un sector de grandes agricultores de raíz colonial también desempeñó un papel en la modernización de la agricultura del sistema de hacienda, la de Joshua Waddington (1794-1876) sugiere que, a diferencia de la interpretación propuesta por Arnold Bauer ${ }^{108}$, los capitalistas mineros y comerciales extranjeros comenzaron a invertir en grandes haciendas bastante antes de la década de 1870, contribuyendo a un sistema de explotación y producción más moderno de la tierra ${ }^{109}$. Tras un breve paso por Buenos Aires, en 1817 Joshua arribó a Valparaíso como socio y representante de la casa Brittain Waddington y Cía., firma que bajo la tutela gerencial de la matriz bonaerense Winter Brittain \& Cía. - establecida desde 1812 en Buenos Aires-, le permitió a este británico y sus socios realizar operaciones de importación directa al puerto de Valparaíso. Posteriormente se independizó y formó su propia casa comercial bajo el nombre de Waddington, Templeman \& Cía. Estas operaciones comerciales fueron la fuente inicial de su riqueza, con la que pudo incursionar en otros sectores, como el naviero, financiero (e.g. actuando como habilitador), seguros ${ }^{110}$, corretaje de propiedades urbanas ${ }^{111}$, ferrocarriles ${ }^{112}$, gas y el sector minero ${ }^{113}$. En todas estas actividades tuvo una destacada participación, llegando, incluso, a ser catalogado como "el más poderoso capitalista de Valparaíso"114. Su inversión en el agro se materializó en el fundo Telégrafo (Huasco), pero mucho más significativamente en la hacienda San Isidro de Limache, muy temprano, en $1833^{115}$, la que destacaba por su considerable producción de trigo. Además, participó en el comercio exportador de harina a través de

${ }^{108}$ Bauer, Chilean Rural..., op. cit., p. 179.

${ }^{109}$ Dicho esto, y a colación con la conexión entre fortunas mineras y su posible participación en la modernización, o no, del agro chileno antes de 1855, el caso de Joshua Waddington parece haber sido bastante excepcional. En efecto, de los otros grandes empresarios mineros que invirtieron en la agricultura durante este periodo, nos referimos a Ramón Subercaseaux, Francisco Ignacio Ossa, Matías Cousiño, Bernardo del Solar y Francisco Videla, no pudimos encontrar mayor evidencia que los relacione con alguna modernización del sector agrícola antes de 1855, aunque justo es mencionar las inversiones de Ramón Subercaseaux en ferrocarriles (véase debajo), que sin dudas ayudaron a modernizar el sector.

${ }^{110}$ Joshua Waddington, junto a otros ciento dieciséis inversionistas, fue un pionero en este mercado, invirtiendo y fundando la Compañía Chilena de Seguros, primera empresa chilena en este rubro.

${ }^{111}$ Antecedentes parciales que hemos recopilado indican que entre 1820 y 1870 Joshua Waddington invirtió más de $£ 30.000$ en la compra de a lo menos treinta y ocho propiedades localizadas en distintos puntos de la ciudad de Valparaíso, así como en la venta de cincuenta y siete propiedades en el mismo puerto, muchas de ellas subdivisiones de las anteriormente compradas. Archivo Notarios de Valparaíso, vol. 30, 34, 35, 38, 39, $45,47,48,51,53,57,61,63,65,66,70,71,72,74,75,77,78,86,89,93,98,99,100,105,107,108,109$, $111-118,120,121,122,124,125,129,133,134,144,147$.

112 Joshua Waddington fue uno de los inversionistas mayoritarios en la formación de la Compañía del Ferrocarril entre Santiago y Valparaíso, que incluía una estación prácticamente a las puertas de su hacienda San Isidro.

${ }^{113}$ Respecto de inversiones en el sector minero, entre varias de ellas, cabe destacar que en 1832 Joshua Waddington se hizo acreedor de algunas minas propiedad de la Asociación de Minas la Chilena, mientras que en 1839 Plácido José Alfaro le cedió y traspasó la mitad del establecimiento y minas de Caleu (Villa de los Andes), a modo de cancelación de una deuda con Joshua Waddington. ANV, vol. 38, Valparaíso, 31 enero 1832; ANV, vol. 51, Valparaíso, 06/04/1839. Joshua Waddington llegó incluso a figurar entre los diez principales exportadores de plata piña de Valparaíso entre 1810 y 1840 . Luz María Méndez, La exportación minera en Chile, 1800-1840, Santiago, Editorial Universitaria, 2004, pp. 200-201.

${ }^{114}$ Edwards, op. cit., pp. 132-133.

${ }^{115} \mathrm{Y}$ en efecto, así quedó consignada en el catastro de 1832-1834, ya bajo su nombre. Otras haciendas en las que invirtió fueron Caleu, en la Villa los Andes. ANV, vol. 48, Valparaíso, 9 de agosto de 1836. 
su casa comercial y en asociación con Guillermo G. Morhead y Diego Whitehead. Con ellos firmó sendos contratos con varios molineros de Santiago y Concepción para asegurar la compra de toda la harina que produjesen, para su posterior exportación ${ }^{116}$. Pero quizá lo más relevante de su emprendimiento agrícola fue la inversión para la construcción de un canal de regadío en la zona en $1843^{117}$, una de las iniciativas más tempranas de modernización en el agro chileno. Los alcances de esta obra de veinticuatro leguas de extensión entre Calera y Limache, avaluada el año 1859 en poco más de cincuenta y siete mil libras ${ }^{118}$ (unos $\$ 285.000$ ), fueron sobresalientes, pues permitieron la recuperación y habilitación de tierras cultivables que favorecieron el desarrollo y experimentación en las actividades agroindustriales como fue el caso de la viña europea, la lechería perfeccionada y las plantaciones de eucaliptus. Fruto de estas inversiones, el ingreso anual de la hacienda San Isidro pasó de \$2.000 en 1833 a \$13.000 en 1852, ejemplificando así otro caso de un agricultor modernizador con fortuna ascendente en el agro chileno para el periodo estudiado. Finalmente, cabe destacar que ligado al tema del agua, pero esta vez en el sector urbano, Joshua Waddington, junto a otros inversionistas, fundó también una compañía destinada a la construcción de pozos ${ }^{119}$.

Al terminar esta sección, cabe destacar que muchos de los grandes hacendados que hemos mostrado en las tablas precedentes fueron socios activos de la primera Sociedad de Agricultura, predecesora de la SNA. Entre ellos, los nombres más frecuentes que se citaban en la lista de asistentes de las sesiones de la SA estaban: Francisco Ignacio Ossa, Ramón Ovalle, Juan de Dios Mendiburu ${ }^{120}$, José Miguel Irarrázabal, José Rafael Larraín, Rafael Larraín Moxó, Santiago Larraín, José Francisco Cerda, Agustín Eyzaguirre, Juan Agustín Alcalde, Pedro Palazuelos, Agustín Nataniel Cox, Ramón Subercaseaux, José Ángel Ortúzar, Santiago Concha, Juan de la Cruz Gandarillas, Joshua Waddington (socio honorario), entre otros ${ }^{121}$. A su vez, varios de ellos fueron socios fundadores de la primera SA, como, por ejemplo, Francisco Ignacio Ossa, Ramón Ovalle y Juan de Dios Mendiburu, mientras que otros tantos ocuparon cargos en las primeras directivas, como Rafael Larraín Moxó (presidente), José Miguel Irarrázabal (vicepresidente), entre otros. Finalmente, otros nombres ilustres, sin ser grandes hacendados, figuran también como asistentes regulares de las asambleas de la SA, destacando entre ellos Ignacio Domeyko, Claudio Gay y Alexander Caldcleugh.

${ }^{116}$ Para algunos ejemplos, véase ANV, vol. 88, Valparaíso, 10 de marzo de 1850; ANV, vol. 88, Valparaíso, 13 de marzo de 1850 .

${ }^{117}$ La información sobre Joshua Waddington y la hacienda San Isidro proviene principalmente de ANCHANV, vols. 29, 30, 34, 37, 38, 39, 40, 43 y 121. Sobre el canal Waddington véase también Luis Correa Vergara, La agricultura en Chile, Santiago, Editorial Nascimiento, 1938, tomo 3, pp. 53-55.

${ }^{118}$ ANV, vol. 121. Valparaíso, 5 de agosto de 1859.

${ }^{119}$ ANV, vol. 53, Valparaíso, 16 de junio de 1840.

${ }^{120}$ De acuerdo con Sergio Villalobos, Origen y ascenso de la burguesía chilena, Santiago, Editorial Universitaria, 2006, pp. 37-40, la familia Mendiburu era una de las dos familias más ricas de Chile a fines del periodo colonial. En nuestros listados de los hacendados más acaudalados de los años 1830 y 1850 siguen figurando entre los top 48 de Chile, lo que, una vez más, confirma la persistencia de las élites coloniales después de la Independencia.

${ }^{121}$ Listado confeccionado con la lista regular de asistentes reportada sistemáticamente en El Agricultor, varios números 1838-1848. 


\section{FORTUNAS AGRÍCOLAS VERSUS FORTUNAS NACIONALES}

Llegado este punto, una pregunta relevante es: ¿qué tan prominentes eran las fortunas del sector agrícola dentro del total de grandes fortunas de la economía chilena entre c. 1832 y 1852? Dicho de otra manera: ¿constituían los propietarios agrícolas que hemos listado en las secciones precedentes los hombres y mujeres más ricos de Chile entre 1832 y 1852 ? De acuerdo con Arnold Bauer, a mediados del siglo xix la mayoría de las más grandes fortunas chilenas seguían estando fuertemente relacionadas con la posesión de propiedades agrarias ${ }^{122}$. Por su parte, sabemos también que el empresariado minero durante la Colonia era un grupo relativamente marginal, si se compara al menos con la élite terrateniente ${ }^{123}$. Durante las primeras tres décadas de la República (c. 1810-1840) el sector minero, si bien mostró algo de dinamismo, no llegó a ser tan importante como lo sería durante la segunda mitad del siglo XIX, por lo que podemos asumir que las fortunas mineras antes de 1840 no estaban entre las mayores fortunas de Chile. No habiendo en Chile otro sector generador de grandes fortunas nacionales (i.e. el sector externo estaba principalmente reservado a extranjeros ${ }^{124}$, mientras que el industrial era marginal), el argumento de Arnold Bauer parece plausible, al menos hasta c. 1850.

Dicho esto, sabemos también que, exactamente treinta años después del periodo cubierto por el tercer catastro, en 1882, cuando El Mercurio publicó una famosa lista de las principales fortunas chilenas a ese año, las 'nuevas fortunas' (provenientes de la minería, la industria y el comercio) representaban un $84 \%$ del total de grandes fortunas, mientras que las 'antiguas' (provenientes de la agricultura), solo un $15 \%{ }^{125}$. Vale decir, entre principios de la década de 1830 e inicios de la de 1880 , nuevas fortunas emergieron en Chile fruto de actividades mineras principalmente, y con una rapidez abismante, lo que se ha denominado la 'primera generación de la burguesía chilena' ${ }^{126}$. La producción de plata y cobre devino en primordial durante este periodo, y varios empresarios chilenos entraron de lleno al sector productivo minero (no así en el de exportación, que siguió estando principalmente en manos de empresarios extranjeros). No sabemos con certeza cuándo exactamente las nuevas fortunas vinculadas al sector minero sobrepasaron a las antiguas fortunas vinculadas al sector agrícola, pero es razonable que esto no hubiese ocurrido antes de inicios de la década de 1850, cuando la red ferroviaria vinculada al sector minero era todavía inexistente. Vale decir, con toda seguridad con posterioridad a nuestro último catastro de 1852. Para complicar aún más las cosas, aparejado al auge minero de los decenios 1850-1870, hubo también un nuevo impulso al sector agrícola que lo abastecía, y que se vio robustecido poco antes del final de nuestro periodo de estudio cuando Chile comenzó a exportar en grande trigo y harina a California y Australia (un boom corto, pero que coincide plenamente con el periodo en el cual se ejecutó el tercer catastro). Este boom, sin duda, devino en nueva fuente de

\footnotetext{
${ }^{122}$ Bauer, Expansión económica..., op. cit.

${ }^{123}$ Villalobos, Origen y ascenso..., op. cit., pp. 41-45; Edwards, op. cit., pp. 8-11; Nazer, op. cit.

124 Eduardo Cavieres, Comercio chileno y comerciantes ingleses 1820-1880: un ciclo de historia económica, Valparaíso, Universidad Católica de Valparaíso, Instituto de Historia, 1988, p. 31.

${ }^{125}$ Nazer, op. cit., p. 60.

${ }^{126}$ Villalobos, Origen y ascenso..., op. cit., p. 49; Cavieres, op. cit., p. 231.
} 
enriquecimiento para el sector agrario, tal como lo demuestra el aumento explosivo de los ingresos listados en la tabla 8. Finalmente, en muchos casos no existe la dicotomía élite terrateniente versus élite minera, pues los empresarios chilenos diversificaron sus carteras de inversión tempranamente.

En cualquier caso, no antes de la década de 1830 se cree que comienzan a emerger grandes fortunas nacionales vinculadas al sector cuprífero y argentífero en Chile ${ }^{127}$. Muchas de ellas estaban ligadas a extranjeros establecidos en Chile (e.g. el caso de Joshua Waddington ya analizado), pero muchos chilenos incursionaron en el sector también. De acuerdo con Ricardo Nazer, los principales empresarios chilenos que emergieron primordialmente del sector minero desde la década de 1830 fueron: Ramón Goyenechea, Juan José Echeverría, Bernardo del Solar, José Tomás Urmeneta, Francisco Ignacio Ossa, Ramón Subercaseaux, Mariano Aristía, Francisco Garín, Miguel Gallo, José María Codecido, Pedro León Gallo, Matías Cousiño, Agustín Edwards Ossandón, Joaquín Edwards, Maximiano Errázuriz, Pedro Díaz Gana, José Santos Ossa, José Antonio Moreno, Ramón Ignacio Goyenechea, Gregorio Ossa, Ramón Ovalle, Adrián Mandiola, Jorge Rojas Miranda y José Ramón Ossa. Cotejando estos nombres con nuestros listados de grandes latifundistas, podemos constatar que prácticamente ninguno de ellos figuraba entre los terratenientes más potentados de la década de 1830. Sin embargo, varios de ellos devinieron en prominentes propietarios de fundos rurales entre la década de 1840 e inicios del decenio 1850. Es decir, gracias a inversiones en el sector agrícola financiadas con actividades mineras, devinieron también en miembros de la élite terrateniente, muchos de ellos ubicados, incluso, entre las cuarenta y ocho mayores fortunas del agro chileno que hemos listado para el catastro de 1852. Por ejemplo, Ramón Subercaseaux obtuvo el tercer mayor ingreso del sector agrícola en Chile; Francisco Ignacio Ossa $^{128}$ rankeaba sexto dentro del total de propietarios agrícolas de ese año; Matías Cousiño lo hacía en el lugar dieciséis; mientras que Bernardo del Solar figura en el notorio lugar veinticinco de las grandes fortunas agrícolas chilenas. Es decir, de la lista de las principales veinticinco nuevas fortunas mineras aportada por Ricardo Nazer, cuatro de ellos se ubican en el top 25 de los mayores ingresos agrícolas de 1852 también. Adicionalmente, cotejando nuestros datos con los de Luz María Méndez, ${ }^{129}$ podemos concluir que otras grandes fortunas mineras, como Francisco Videla (gran exportador de plata) también devino en uno de los grandes terratenientes de Chile (top 24 en 1852). Nuestros datos, por tanto, confirman la hipótesis de Ricardo Nazer, en cuanto a que el nuevo empresariado minero diversificó fuerte su cartera hacia el sector agrícola (y otros sectores también $)^{130}$, pero que esto ocurrió solo a partir de los años 1840 .

¿Qué ocurrió con la inversión de estos "nuevos terratenientes" en otros sectores de la economía? Sabemos que la diversificación de inversiones abarcaba también el sector financiero, el sector transporte y los sectores alumbrado y agua potable, entre otros. Ya

${ }^{127}$ Nazer, op. cit., p. 67.

${ }^{128}$ Uno de los mayores exportadores de plata de Chile en el periodo bajo estudio. Méndez, op. cit.

${ }^{129}$ Op. cit.

${ }^{130}$ Los casos más emblemáticos mencionados por Nazer, op. cit., p. 70, son José Tomás Urmeneta, Joaquín Edwards y Matías Cousiño. 
mencionamos los casos de Joshua Waddington y Rafael Larraín Moxó, muy ilustrativos de esta diversificación por parte de empresarios con inversiones en el sector agrario. En la misma línea, gracias al reciente trabajo de Roberto Araya ${ }^{131}$, sabemos, también, por ejemplo, que de los empresarios terratenientes y mineros arriba mencionados, durante los años 1840 y 1850, Matías Cousiño (además de invertir en tierra y minería) ${ }^{132}$ invirtió en la Compañía Chilena de Seguros y El Porvenir de las Familias (también del sector seguros), en el Ferrocarril entre Santiago y Valparaíso -emprendimiento del cual también participó Ramón Subercaseaux-y otros proyectos ferroviarios como el camino ferrocarril de Copiapó y el Ferrocarril del Sur e, incluso, incursionó en la banca a través de inversiones en Benzanilla Maclure \& Co. y el Banco de Depósitos y Descuentos de Valparaíso, entidad financiera de la cual también fue accionista Francisco Ignacio Ossa. Finalmente, los trabajos de otros autores como Ricardo Nazer y Eduardo Cavieres confirman también lo dicho anteriormente, en el sentido que las nuevas élites económicas de Chile de mediados del siglo XIX capitalizaron sus utilidades invirtiendo en varios sectores de la economía, articulando en el intertanto imbricadas redes comerciales.

\section{CONCLUSIONES}

Desde fines de la época colonial y hasta principios del decenio de 1850, el periodo cubierto por este artículo, el sector agrícola fue el más importante de la economía nacional, independientemente del indicador que tomemos: porcentaje de la población rural sobre el total; participación de la fuerza laboral agrícola sobre el total nacional, o participación del PIB agrícola sobre el PIB total chileno. No obstante, la historiografía del sector agrario chileno para las primeras décadas de la República es escasa y fragmentaria, por las razones ya esgrimidas. Para subsanar parte de esta laguna historiográfica, para este estudio hemos recopilado y procesado toda la información recogida en los tres primeros catastros agrícolas de Chile, ejecutados entre 1832 y 1852, para lo cual ingresamos casi medio millón de registros. Nuestra base de datos es única para cualquier país de la región: Chile fue un pionero en las estadísticas agrarias antes de 1850. Adicionalmente, usando otras fuentes poco exploradas hasta ahora, como los órganos oficiales de las primeras dos sociedades de agricultura, hemos caracterizado al sector agrario en su conjunto, confirmando un gran nivel de atraso, al menos relativo a Europa.

Como resultado, hemos podido constatar una muy mala distribución tanto del ingreso agrícola como de la tierra en Chile para este periodo. Asimismo, hemos elaborado un preciso listado de las élites agrarias de Chile para 1832, 1838 y 1852, identificando a los principales terratenientes de Chile, varios de ellos desconocidos para la historiografía.

\footnotetext{
${ }^{131}$ Roberto Araya, La elite económica y su conformación empresarial S. A. Artífices y beneficiarios de la modernización Santiago y Valparaíso (1854-1875), tesis de Magíster en Historia, Santiago, Universidad de Santiago de Chile, cuadro 4.

${ }^{132}$ Cuenta entre una de sus inversiones mineras la compra del 20\% de las acciones de la Sociedad Chilena de Fundiciones (1856), bajo la figura de la firma comercial Cousiño \& Garland, empresa formada para la compra y beneficio de minerales de cobre, plata o cualquier otro mineral, de la cual Bernardo del Solar se hizo acreedor de igual porcentaje de acciones. ANV, vol. 274, Santiago, 12 de mayo de 1856.
} 
Adicionalmente, hemos caracterizado de forma certera las principales propiedades agrarias de Chile, al menos en cuanto a su extensión, posesión de ganado (mayor y menor) y viñedos se refiere. Más importante aún, nuestros listados de la élite agraria chilena para 1832-1852 nos permitieron cotejar dicha información con todos los miembros de la élite de fines del periodo colonial. La evidencia así disponible muestra que hay una tremenda persistencia de las élites económicas entre fines de la Colonia y principios de la República. El desplazamiento de las viejas élites coloniales pareciera haber sido mucho más lento de lo que se creía hasta ahora y con toda seguridad podemos ubicarlo recién en la segunda mitad del siglo XIX. La Independencia chilena no produjo ningún quiebre significativo entre el régimen colonial y el republicano, al menos en términos de la composición de la élite económica entre ambos periodos, ni tampoco en cuanto a distribución de su ingreso y riqueza se refiere. Esta persistencia de la élite colonial podría explicar, en parte, la persistencia de técnicas agrícolas rudimentarias en el agro chileno y la falta de modernización del sector hasta 1850, aunque cierto es que hubo importantes excepciones. Finalmente, cabe mencionar que nuestro trabajo también permite demostrar nexos significativos y persistentes entre la élite económica y la política en las primeras décadas después de la independencia; en breve, buena parte de la élite terrateniente ocupó asientos parlamentarios y altos cargos de gobierno, situación que persistió al menos hasta entrado el siglo $\mathrm{xx}^{133}$.

${ }^{133}$ Entre 1874 y 1902, un 50\% y un 57\% de los congresistas chilenos, respectivamente, eran propietarios de a lo menos una gran hacienda. Bauer, Chilean Rural..., op. cit., p. 246. 